\title{
Characterization of "dead-zone" eddies in the eastern tropical North Atlantic
}

\author{
Florian Schütte $^{1}$, Johannes Karstensen ${ }^{1}$, Gerd Krahmann ${ }^{1}$, Helena Hauss ${ }^{1}$, Björn Fiedler ${ }^{1}$, Peter Brandt ${ }^{1,2}$, \\ Martin Visbeck $^{1,2}$, and Arne Körtzinger ${ }^{1,2}$ \\ ${ }^{1}$ GEOMAR Helmholtz Centre for Ocean Research Kiel, Kiel, Germany \\ ${ }^{2}$ Christian-Albrechts-Universität zu Kiel, Kiel, Germany \\ Correspondence to: Florian Schütte (fschuette@geomar.de)
}

Received: 10 February 2016 - Published in Biogeosciences Discuss.: 22 February 2016

Revised: 10 September 2016 - Accepted: 30 September 2016 - Published: 28 October 2016

\begin{abstract}
Localized open-ocean low-oxygen "dead zones" in the eastern tropical North Atlantic are recently discovered ocean features that can develop in dynamically isolated water masses within cyclonic eddies (CE) and anticyclonic modewater eddies (ACME). Analysis of a comprehensive oxygen dataset obtained from gliders, moorings, research vessels and Argo floats reveals that "dead-zone" eddies are found in surprisingly high numbers and in a large area from about 4 to $22^{\circ} \mathrm{N}$, from the shelf at the eastern boundary to $38^{\circ} \mathrm{W}$. In total, 173 profiles with oxygen concentrations below the minimum background concentration of $40 \mu \mathrm{mol} \mathrm{kg}-1$ could be associated with 27 independent eddies (10 CEs; 17 ACMEs) over a period of 10 years. Lowest oxygen concentrations in CEs are less than $10 \mu \mathrm{mol} \mathrm{kg}{ }^{-1}$ while in ACMEs even suboxic $\left(<1 \mu \mathrm{mol} \mathrm{kg}^{-1}\right)$ levels are observed. The oxygen minimum in the eddies is located at shallow depth from 50 to $150 \mathrm{~m}$ with a mean depth of $80 \mathrm{~m}$. Compared to the surrounding waters, the mean oxygen anomaly in the core depth range (50 and $150 \mathrm{~m}$ ) for CEs (ACMEs) is $-38(-79) \mu \mathrm{mol} \mathrm{kg}{ }^{-1}$. North of $12^{\circ} \mathrm{N}$, the oxygen-depleted eddies carry anomalously low-salinity water of South Atlantic origin from the eastern boundary upwelling region into the open ocean. Here water mass properties and satellite eddy tracking both point to an eddy generation near the eastern boundary. In contrast, the oxygen-depleted eddies south of $12^{\circ} \mathrm{N}$ carry weak hydrographic anomalies in their cores and seem to be generated in the open ocean away from the boundary. In both regions a decrease in oxygen from east to west is identified supporting the en-route creation of the low-oxygen core through a combination of high productivity in the eddy surface waters and an isolation of the eddy cores with respect to lateral oxy-
\end{abstract}

gen supply. Indeed, eddies of both types feature a cold sea surface temperature anomaly and enhanced chlorophyll concentrations in their center. The low-oxygen core depth in the eddies aligns with the depth of the shallow oxygen minimum zone of the eastern tropical North Atlantic. Averaged over the whole area an oxygen reduction of $7 \mu \mathrm{mol} \mathrm{kg}{ }^{-1}$ in the depth range of 50 to $150 \mathrm{~m}$ (peak reduction is $16 \mu \mathrm{mol} \mathrm{kg} \mathrm{kg}^{-1}$ at $100 \mathrm{~m}$ depth) can be associated with the dispersion of the eddies. Thus the locally increased oxygen consumption within the eddy cores enhances the total oxygen consumption in the open eastern tropical North Atlantic Ocean and seems to be an contributor to the formation of the shallow oxygen minimum zone.

\section{Introduction}

The eastern tropical North Atlantic (ETNA: 4 to $22^{\circ} \mathrm{N}$ and from the shelf at the eastern boundary to $38^{\circ} \mathrm{W}$; Fig. 1) off northwestern Africa is one of the biologically most productive areas of the global ocean (Chavez and Messié, 2009; Lachkar and Gruber, 2012). In particular, the eastern boundary current system close to the northwestern African coast is a region where northeasterly trade winds force coastal upwelling of cold, nutrient-rich waters, resulting in high productivity (Bakun, 1990; Lachkar and Gruber, 2012; Messié et al., 2009; Pauly and Christensen, 1995). The ETNA is characterized by a weak large-scale circulation and instead dominated by mesoscale variability (here referred to as eddies; Brandt et al., 2015; Mittelstaedt, 1991). Traditionally the ETNA is considered to be "hypoxic", with minimal oxy- 

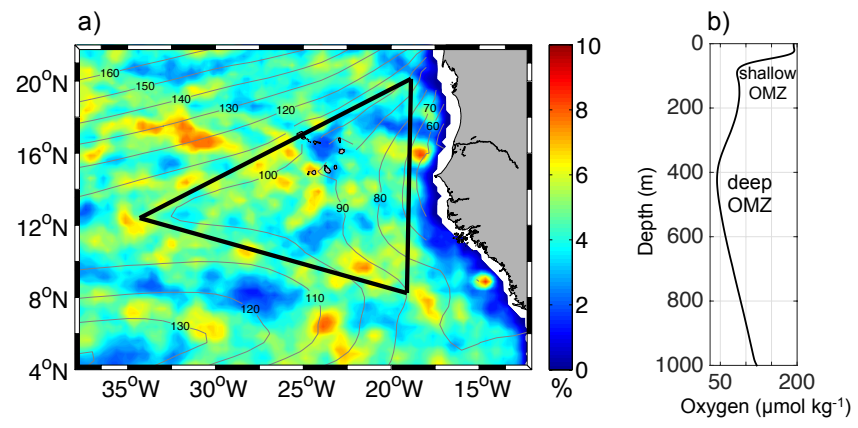

Figure 1. (a) Map of the ETNA including contour lines of the oxygen minimum of the upper $200 \mathrm{~m}$ (in $\mu \mathrm{mol} \mathrm{kg}^{-1}$ ) as obtained from the MIMOC climatology (Schmidtko et al., 2013). The color indicates the percentage of "dead-zone" eddy coverage per year. The black triangle defines the SOMZ. (b) Mean vertical oxygen profile of all profiles within the SOMZ showing the shallow oxygen minimum centered around $80 \mathrm{~m}$ depth and the deep oxygen minimum centered at $450 \mathrm{~m}$ depth.

gen concentrations of marginally below $40 \mu \mathrm{mol} \mathrm{kg}{ }^{-1}$ (e.g., Stramma et al., 2009; Fig. 1a). The large-scale ventilation and oxygen consumption processes of thermocline waters in the ETNA result in two separate oxygen minima (Fig. 1b): a shallow one with a core depth of about $80 \mathrm{~m}$ and a deep one at a core depth of about $450 \mathrm{~m}$ (Brandt et al., 2015; Karstensen et al., 2008). The deep minimum is the core of the so-called oxygen minimum zone (OMZ) and is primarily created by sluggish ventilation of the respective isopycnals (Luyten et al., 1983; Wyrtki, 1962). It extends from the eastern boundary into the open ocean and is located in the so-called shadow zone of the ventilated thermocline, with the more energetic circulation of the subtropical gyre in the north and the equatorial region in the south (Karstensen et al., 2008; Luyten et al., 1983). The shallow oxygen minimum intensifies from the Equator towards the north with minimal values near the coast at about $20^{\circ} \mathrm{N}$ (Brandt et al., 2015; Fig. 1a). It is assumed that the shallow oxygen minimum originates from enhanced biological productivity and an increased respiration associated with sinking particles in the water column (Brandt et al., 2015; Karstensen et al., 2008; Wyrtki, 1962).

The eddies act as a major transport agent between coastal waters and the open ocean (Schütte et al., 2016a), which is a well-known process for all upwelling areas in the world oceans (Capet et al., 2008; Chaigneau et al., 2009; CorreaRamirez et al., 2007; Marchesiello et al., 2003; Nagai et al., 2015; Schütte et al., 2016a; Thomsen et al., 2015). In the ETNA, most eddies are generated near the eastern boundary; Rossby wave dynamics and the basin-scale circulation force these eddies to propagate westwards (Schütte et al., 2016a). Open-ocean eddies with particularly high South Atlantic Central Water (SACW) fractions in their cores have been found far offshore in regions dominated by the much saltier North Atlantic Central Water (NACW; Karstensen et al., 2015; Pastor et al., 2008). Weak lateral exchange across the eddy boundaries is most likely the reason for the isolation (Schütte et al., 2016a). The impact of eddy transport on the coastal productivity (equivalent to other upwelling-related properties) was investigated by Gruber et al. (2011), who were able to show that high (low) eddy-driven transports of nutrient-rich water from the shelf into the open-ocean results in lower (higher) biological production on the shelf. Besides acting as export agents for coastal waters and conservative tracers, coherent eddies have been reported to establish and maintain an isolated ecosystem changing non-conservative tracers with time (Altabet et al., 2012; Fiedler et al., 2016; Hauss et al., 2016; Karstensen et al., 2015; Löscher et al., 2015). Coherent/isolated mesoscale eddies can exist over periods of several months or even years (Chelton et al., 2011). During that time the biogeochemical conditions within these eddies can evolve very different from the surrounding water masses (Fiedler et al., 2016). Hypoxic to suboxic oxygen levels have been observed in cyclonic eddies (CEs) and anticyclonic mode-water eddies (ACMEs) at shallow depth and just beneath the mixed layer (ML, about 50 to $100 \mathrm{~m}$; Karstensen et al., 2015). The creation of the low-oxygen cores in the eddies have been attributed to the combination of several factors (Karstensen et al., 2015): high productivity in the surface waters of the eddy (Hauss et al., 2016; Löscher et al., 2015), enhanced respiration of sinking organic material at subsurface depth (Fiedler et al., 2016; Fischer et al., 2016) and an "isolation" of the eddy core from exchange with surrounding and better-oxygenated water (Karstensen et al., 2016). The intermittent nature of the oxygen depletion and the combination of high respiration with sluggish oxygen transport resembles what is known as "dead zone" in other aquatic system (lakes, shallow bays), and therefore the term "dead-zone eddies" has been introduced (Karstensen et al., 2015). So far the profound impacts on behavior of microbial (Löscher et al., 2015) and metazoan (Hauss et al., 2016) communities has been documented inside the eddies. For example, the appearance of denitrifying bacteria, typically absent from the open tropical Atlantic, has been observed (Löscher et al., 2015) via the detection of nirS gene transcripts (the key functional marker for denitrification). However, the close-to-Redfield $\mathrm{N}: \mathrm{P}$ stoichiometry in ACMEs in the ETNA (Fiedler et al., 2016) does not suggest a large-scale net loss of bioavailable nitrogen via denitrification. The key point in changing non-conservative tracers in the eddy cores is the physicalbiological coupling, which is strongly linked to the vertical velocities of submesoscale physics, stimulating primary production (upward nutrient flux) in particular under oligotrophic conditions (Falkowski et al., 1991; Levy et al., 2001; McGillicuddy et al., 2007). The detailed understanding of the physical and biogeochemical processes and their linkage in eddies is still limited (Lévy et al., 2012). Consequently the relative magnitude of eddy-dependent vertical nutrient flux, primary productivity and associated enhanced oxygen consumption or nitrogen fixation/denitrification in the eddy 
cores and accordingly the contribution to the large-scale oxygen or nutrient distribution is fairly unknown.

In order to further investigate the physical, biogeochemical and ecological structure of "dead-zone" eddies, an interdisciplinary field study was carried out in winter 2013/spring 2014 in the ETNA, north of Cape Verde, using dedicated ship, mooring and glider surveys supported by satellite and Argo float data. The analysis of the field study data revealed surprising results regarding eddy metagenomics (Löscher et al., 2015), zooplankton communities (Hauss et al., 2016), carbon chemistry (Fiedler et al., 2016) and nitrogen cycling (Karstensen et al., 2016). Furthermore, analyses of particle flux time series, using sediment trap data from the Cape Verde Ocean Observatory (CVOO), were able to confirm the impact of highly productive "dead-zone" eddies on deep local export fluxes (Fischer et al., 2016). In this paper we investigate "dead-zone" eddies detected from sea level anomaly (SLA) and sea surface temperature (SST) data based on methods described by Schütte et al. (2016a). We draw a connection between the enhanced consumption and associated low-oxygen concentration in eddy cores and the formation of the regional observed shallow oxygen minimum. To assess the influence of oxygen-depleted eddies on the oxygen budget of the upper water column, a sub-region between the ventilation pathways of the subtropical gyre and the zonal current bands of the equatorial Atlantic was chosen and investigated in more detail. This region includes the most pronounced shallow oxygen minimum zone (SOMZ; Fig. 1a). The probability of "dead-zone" eddy occurrence per year is more or less evenly distributed in the ETNA (Fig. 1a). Particularly in the SOMZ there seems to be neither a distinctly high nor an explicitly low "dead-zone" eddy occurrence. Due to the absence of other ventilation pathways in this zone, the influence of "dead-zone" eddies on the shallow oxygen minimum budget may be important and a closer examination worth the effort. We determine the average characteristics of "dead-zone" eddies in the ETNA, addressing their hydrographic features as well as occurrence, distribution, generation and frequency. Based on oxygen anomalies and eddy coverage we estimate their contribution to the oxygen budget of the SOMZ. The paper is organized as follows. Section 2 addresses the different in situ measurements, satellite products and methods we use. Our results are presented in Sect. 3, discussed in Sect. 4 and summarized in Sect. 5.

\section{Data and methods}

\subsection{In situ data acquisition}

For our study we employ a quality-controlled database combining shipboard measurements, mooring data and Argo float profiles as well as autonomous glider data taken in the ETNA. For details on the structure and processing of the database see Schütte et al. (2016a). For this study we ex-

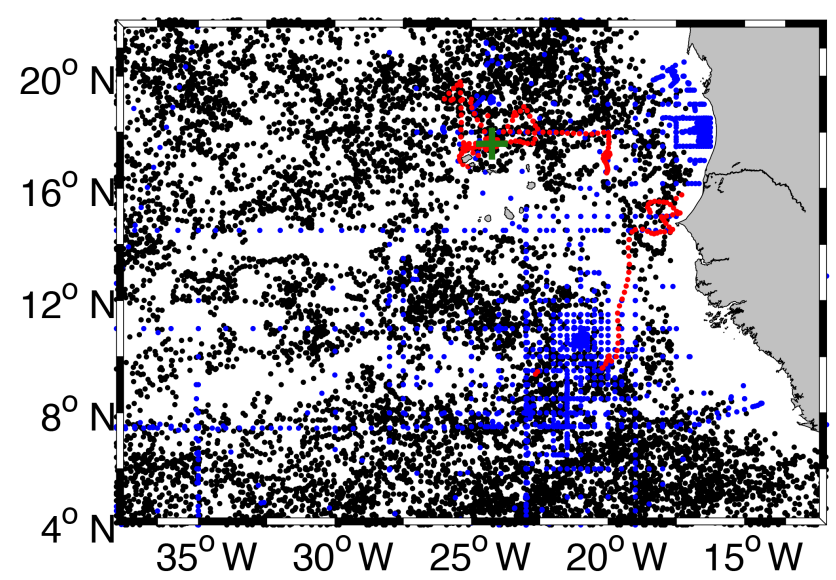

Figure 2. Map of the ETNA containing all available profiles between 1998 and 2014. The green cross marks the CVOO position, blue dots mark shipboard conductivity-temperature-depth (CTD) stations, red dots mark the locations of glider profiles and black dots locations of Argo float profiles.

tended the database in several ways. The region was expanded to now cover the region from 0 to $22^{\circ} \mathrm{N}$ and 13 to $38^{\circ} \mathrm{W}$ (see Fig. 2). We then included data from five recent ship expeditions (RV Islandia ISL_00314, RV Meteor M105, M107, M116, M119), which sampled extensively within the survey region. Data from the two most recent deployment periods of the CVOO mooring from October 2012 to September 2015 as well as Argo float data for the years 2014 and 2015 were also included. Furthermore, oxygen measurements of all data sources were collected and integrated into the database. As the last modification of the database we included data from four autonomous gliders that were deployed in the region and sampled two ACMEs and one CE. Glider IFM11 (deployment ID: ifm11_dep101) was deployed on 13 March 2010. It covered the edge of an ACME on 20 March and recorded data in the upper $500 \mathrm{~m}$. Glider IFM05 (deployment ID: ifm05_depl08) was deployed on 13 June 2013. It crossed a CE on July 26 and recorded data down to $1000 \mathrm{~m}$ depth. IFM12 (deployment ID: ifm12_depl02) was deployed on 10 January 2014 north of the Cape Verde island São Vicente and surveyed temperature, salinity and oxygen to $500 \mathrm{~m}$ depth. IFM13 (deployment ID: ifm13_depl01) was deployed on 18 March 2014 surveying temperature, salinity and oxygen to $700 \mathrm{~m}$ depth. IFM12 and IFM13 were able to sample three complete sections through an ACME. All glider data were internally recorded as a time series along the flight path, while for the analysis the data was interpolated onto a regular pressure grid of $1 \mathrm{dbar}$ resolution (see also Thomsen et al., 2015). Gliders collect a large number of relatively closely spaced slanted profiles. To reduce the number of dependent measurements, we limited the number of glider profiles to one every $12 \mathrm{~h}$. All four autonomous gliders were equipped with Aanderaa optodes (3830) installed in the aft 
section of the devices. A recalibration of the optode calibration coefficients was determined on dedicated conductivitytemperature-depth (CTD) casts following the procedures of (Hahn et al., 2014). These procedures also estimate and correct the delays caused by the slow optode response time (more detailed information can be found in Hahn et al., 2014, and Thomsen et al., 2015). As gliders move through the water column the oxygen measurements are not as stable as those from moored optodes analyzed by Hahn et al. (2014). We thus estimate their measurement error to about $3 \mu \mathrm{mol} \mathrm{kg}{ }^{-1}$. The processing and quality control procedures for temperature and salinity data from shipboard measurements, mooring data and Argo floats has already been described by Schütte et al. (2016a). The processing of the gliders' temperature and salinity measurements is described in Thomsen et al. (2015). Oxygen measurements of the shipboard surveys were collected with Seabird SBE 43 dissolved oxygen sensors attached to Seabird SBE 9plus or SBE 19 CTD systems. Sampling and calibration followed the procedures detailed in the GO-SHIP manuals (Hood et al., 2010). The resulting measurement error were $\leq 1.5 \mu \mathrm{mol} \mathrm{kg}{ }^{-1}$. Within the CVOO moorings, a number of dissolved oxygen sensors (Aanderaa optodes type 3830) were used.

Calibration coefficients for moored optodes were determined on dedicated CTD casts and additional calibrated in the laboratory with water featuring $0 \%$ air saturation before deployment and after recovery following the procedures described by Hahn et al. (2014). We estimate their measurement error at $<3 \mu \mathrm{mol} \mathrm{kg}{ }^{-1}$. For the few Argo floats equipped with oxygen sensors a full calibration is usually not available and only a visual inspection of the profiles was done before including the data into the database. The different manufacturers of Argo float oxygen sensors specify their measurement error at least better than $8 \mu \mathrm{mol} \mathrm{kg}^{-1}$ or $5 \%$, whichever is larger. Note that early optodes can be significantly outside of this accuracy range, showing offsets of $15-20 \mu \mathrm{mol} \mathrm{kg}^{-1}$, in some cases even higher.

As a final result the assembled in situ database of the ETNA contains 15059 independent profiles (Fig. 2). All profiles include temperature, salinity and pressure measurements while $38.5 \%$ of all profiles include oxygen measurements. The database is composed of $13 \%$ shipboard, $22.5 \%$ CVOO mooring, $63 \%$ Argo float and $1.5 \%$ glider profiles. To determine the characteristics of different eddy types from the assembled profiles, we separated them into CEs, ACMEs and the "surrounding area" not associated with eddy-like structures following the approach of Schütte et al. (2016a).

\subsection{Satellite data}

We detected and tracked eddies following the procedures described in Schütte et al. (2016a). In brief we used 19 years of the delayed-time "all-sat-merged" reference dataset of SLA (version 2014). The data are produced by Ssalto/Duacs and distributed by AVISO (Archiving, Validation, and In- terpretation of Satellite Oceanographic), with support from CNES (http://www.aviso.altimetry.fr/duac/). We used the multi-mission product, which is mapped on a $1 / 4^{\circ} \times 1 / 4^{\circ}$ Cartesian grid and has a temporal resolution of 1 day. The anomalies were computed with respect to a 19-year mean. The SLA and geostrophic velocity anomalies also provided by AVISO were chosen for the time period January 1998 to December 2014.

For SST the dataset "Microwave Infrared Fusion Sea Surface Temperature" from Remote Sensing Systems (www. remss.com) is used. It is a combination of all operational microwave (MW) radiometer SST measurements (TMI, AMSR-E, AMSR2, WindSat) and infrared (IR) SST measurements (Terra MODIS, Aqua MODIS). The dataset thus combines the advantages of the MW data (through-cloud capabilities) with the IR data (high spatial resolution). The SST values are corrected using a diurnal model to create a foundation SST that represents a 12:00 LT temperature (www.remss.com). Daily data with $9 \mathrm{~km}$ resolution from January 2002 to December 2014 are considered.

For sea surface chlorophyll (Chl) data we use the MODIS/Aqua Level 3 product available at http://oceancolor. gsfc.nasa.gov provided by the NASA. The data were measured via IR and are therefore cloud cover dependent. Daily data mapped on a $4 \mathrm{~km}$ grid from January 2006 to December 2014 are selected.

\subsection{Low-oxygen eddy detection and surface composites}

In order to verify whether low-oxygen concentrations $\left(<40 \mu \mathrm{mol} \mathrm{kg}^{-1}\right)$ at shallow depth (above $200 \mathrm{~m}$ ) are associated with eddies we applied a two step procedure. First, all available oxygen measurements of the combined in situ datasets are used to identify negative oxygen anomalies with respect to the climatology. Next, the satellite-databased eddy detection results (Schütte et al., 2016a) were matched in space and time with the location of anomalously low-oxygen profiles. In this survey the locations of 173 of 180 low-oxygen profiles coincide with surface signatures of mesoscale eddies. Schütte et al. (2016a) showed that ACMEs can be distinguished in the ETNA from "normal" anticyclonic eddies by considering the SST anomaly (cold in case of ACMEs) and sea surface salinity (SSS) anomaly (fresh in case of ACMEs) in parallel to the respective SLA anomaly. The satellite-based estimates of SLA and SST used in this study are obtained by subtracting low-pass filtered (cutoff wavelength of $15^{\circ}$ longitude and $5^{\circ}$ latitude) values from the original data to exclude large-scale variations and preserve only the mesoscale variability (see Schütte et al., 2016a for more detail). All eddy-like structures with low-oxygen profiles are visually tracked in the filtered SLA (sometimes SST data) backward and forward in time in order to obtain eddy propagation trajectories. The surface composites of satellitederived SLA, SST and Chl data consist of $150 \mathrm{~km} \times 150 \mathrm{~km}$ 
(a)

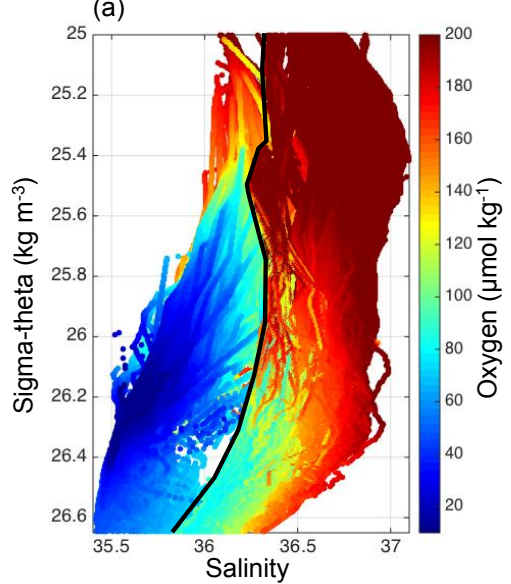

(b)

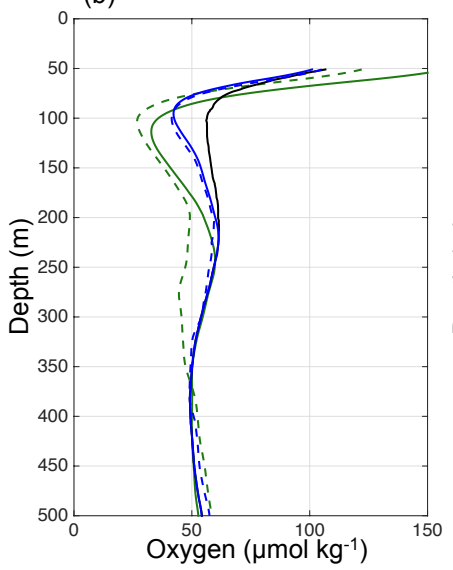

(c)

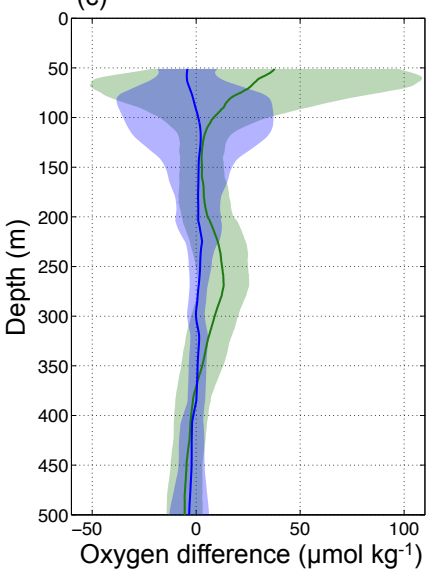

Figure 3. (a) Salinity $-\sigma_{\theta}$ diagram with color indicating the oxygen concentrations. The black line separates the 173 profiles with minimum oxygen concentration of $<40 \mu \mathrm{mol} \mathrm{kg}{ }^{-1}$ (left side/more SACW characteristics) from profiles of the surrounding water (right side/more NACW characteristics), taken from the same devices shortly before and after the encounter with a low-oxygen eddy. (b) Mean oxygen concentration vs. depth of the coastal region (east of $18^{\circ} \mathrm{W}$, solid black line), of all CEs (solid blue line) and all ACMEs (solid green line) with available oxygen measurements. The dashed line represents the reconstructed mean oxygen concentration for the same CEs (blue) and ACMEs (green). (c) Difference between the reconstructed and measured oxygen concentrations in CEs (blue) and ACMEs (green) with associated standard deviation (shaded area).

snapshots around the obtained eddy centers. For construction of the composites the filtered SLA and SST are used as well.

\subsection{Reconstruction of oxygen concentrations in low-oxygen eddy cores}

About $30 \%$ of the profiles from the combined in situ dataset conducted in CEs or ACMEs do not have oxygen measurements available. However, we are only interested in oxygen measurements in isolated CE or ACME cores. These isolated eddy cores carry anomalously low-salinity SACW of coastal origin, while the surrounding waters are characterized by an admixture of more saline NACW (Schütte et al., 2016a). All eddies that show a low-salinity and cold core indicate that (i) they have been generated near the coast and (ii) their core has been efficiently isolated from surrounding waters. The salinity $-\sigma_{\theta}$ diagram (Fig. 3a) of open-ocean (west of $19^{\circ} \mathrm{W}$ ) profiles shows a correlation between low-salinity eddy cores and low-oxygen concentrations. Moreover, it indicated that the oxygen content in the isolated eddies is decreasing from east to west. In order to compensate for missing oxygen measurements on many of the profiles we derive a salinityoxygen relation but also consider the "age" of the eddy (time since the eddy left the eastern boundary) and an oxygen consumption rate within the eddy core. The oxygen consumption rate is estimated from the difference between the observed oxygen and a reference profile (the mean of all profiles east of $18^{\circ} \mathrm{W}$ in the eastern boundary region; Fig. 3a), the distance from the eastern boundary, and the propagation speed ( $3 \mathrm{~km} \mathrm{~d}^{-1}$; see Schütte et al., 2016a). The mean eddy consumption rate is now the difference from the initial oxygen condition and the observed oxygen concentration in the eddy core divided by the eddy age (distance divided by propagation speed). For eddy profiles without oxygen measurements but SACW water mass characteristics (less saline and colder water than surrounding water) we can assume a strong isolation of the eddy and thus a lowering in oxygen. Using the coastal reference profile (Fig. 3), oxygen consumption rate and the distance from the coast an oxygen profile is reconstructed for all isolated CEs and ACMEs. To validate the method we reconstructed the oxygen profiles for the eddies with available oxygen measurements and compared them (Fig. 3b). On average an uncertainty of $\pm 12(16) \mu \mathrm{mol} \mathrm{kg} \mathrm{kg}^{-1}$ is associated with the reconstructed oxygen values (Fig. 3c) of CEs (ACMEs). Depending on the intensity of isolation of the eddy core, lateral mixing could have taken place, which is assumed to be zero in our method. However, this approach enables us to enlarge the oxygen dataset by $30 \%$. We considered the reconstructed oxygen profiles only to estimate the mean structure of oxygen anomaly.

\subsection{Mean vertical oxygen anomaly of low-oxygen eddies and their impact on the SOMZ}

To illustrate mean oxygen anomalies for CEs and ACMEs as a function of depth and radial distance, all oxygen profiles (observed and reconstructed) were sorted with respect to a normalized distance, which is defined as the actual distance of the profile from the eddy center divided by the radius of the eddy (the shape and thus the radius of the eddy are gained from the streamline with the strongest swirl velocity around a center of minimum geostrophic surface velocity). The oxy- 


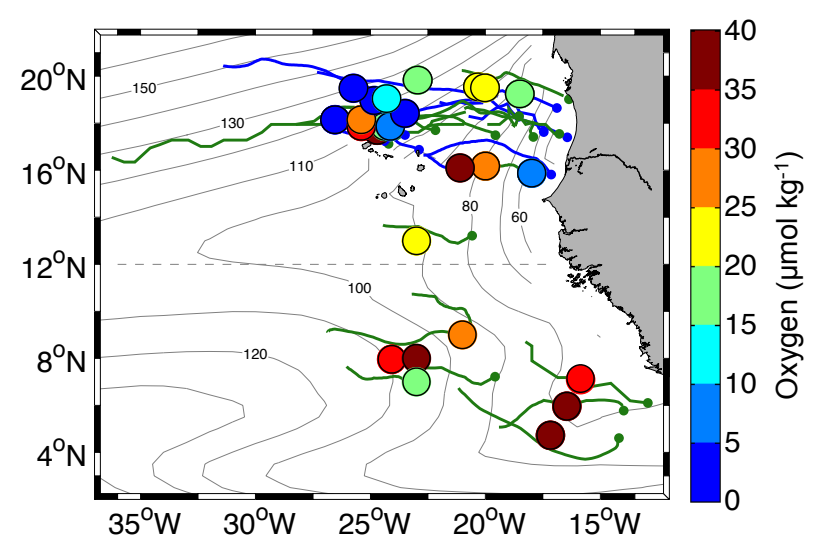

Figure 4. Minimum oxygen concentration (contour lines, $\mu \mathrm{mol} \mathrm{kg}{ }^{-1}$ ) in the ETNA between the surface and $200 \mathrm{~m}$ depth as obtained from the MIMOC climatology (Schmidtko et al., 2013). Superimposed colored dots are all low-oxygen measurements (below $40 \mu \mathrm{mol} \mathrm{kg}^{-1}$ in the upper $200 \mathrm{~m}$ ) which could be associated with eddy-like structures. The size of the dots represents a typical size of the mesoscale eddies. The associated trajectories of the eddies are shown in green for ACMEs and in blue for cyclones. The oxygen concentrations are from the combined dataset of shipboard, mooring, glider and Argo float measurements.

gen profiles were grouped and averaged onto a grid of 0.1 increments between 0 and 1 of the normalized radial distance. Finally a running mean over three consecutive horizontal grid points was applied. A mean oxygen anomaly for the CEs and the ACMEs was constructed by the comparison with the oxygen concentrations in the surrounding waters. To illustrate the influence of the reconstructed oxygen values, the mean oxygen anomaly is also constructed based only on original measured oxygen values, and both anomalies are shown for comparison.

An oxygen deficit profile due to "dead-zone" eddies in the SOMZ is derived by building an oxygen anomaly on density surfaces $\left(\mathrm{O}_{2}{ }^{\prime}\right)$ separating CEs and ACMEs. The derived anomalies are multiplied by the mean number of eddies dissipating in the SOMZ per year $(n)$ and weighted by the area of the eddy compared to the total area of the SOMZ $\left(A_{\text {SOMZ }}=\right.$ triangle in Fig. 1a). Differences in the mean isopycnal layer thickness of each eddy type and the SOMZ are considered by multiplying the result with the ratio of the mean Brunt-Väisälä frequency $\left(\mathrm{N}^{2}\right)$ outside and inside the eddy, resulting in an apparent oxygen utilization rate $\left(\mu \mathrm{mol} \mathrm{kg}{ }^{-1} \mathrm{yr}^{-1}\right)$ due to "dead-zone" eddies in the SOMZ on density layers:

aOUR $=n \mathrm{O}_{2}{ }^{\prime} \frac{\pi r_{\text {Eddy }}^{2} \mathrm{~N}_{\text {SOMZ }}^{2}}{A_{\text {SOMZ }} \mathrm{N}_{\text {Eddy }}^{2}}$,

where $r_{\text {Eddy }}$ is the mean radius of the eddies.

\section{Results}

\subsection{Low-oxygen eddy observation from in situ data}

Several oxygen measurements in the ETNA with anomalously low-oxygen concentrations, which is defined here as an oxygen concentration below $40 \mu \mathrm{mol} \mathrm{kg}^{-1}$ (Stramma et al., 2009) could be identified from Argo floats, ship surveys, glider missions and from the CVOO mooring (Fig. 4). In total, 27 independent eddies with oxygen values $<40 \mu \mathrm{mol} \mathrm{kg}^{-1}$ in the upper $200 \mathrm{~m}$ were sampled with 173 profiles from 25 different platforms (Table 1). Almost all of the observed anomalous low-oxygen values could be associated with mesoscale structures at the sea surface (CEs or ACMEs) from satellite data.

In situ measurements for meridional velocity, temperature, salinity and oxygen of the CVOO mooring during the westward passage of one CE and one ACME with lowoxygen concentrations are chosen to introduce the two different eddy types and their vertical structure based on temporally high-resolution data (Fig. 5). From October 2006 to December 2006 (Fig. 5a), a CE passed the CVOO mooring position on a westward trajectory. At its closest, the eddy center was located about $20 \mathrm{~km}$ north of the mooring. The meridional velocities show a strong cyclonic rotation (first southward, later northward) with velocity maxima between the surface and $50 \mathrm{~m}$ depth at the edges of the eddy. In the core of the $\mathrm{CE}$, the water mass was colder and less saline than the surrounding water, the ML depth is reduced and the isopycnals are shifted upwards. The oxygen content of the eddy core was reduced by about $60 \mu \mathrm{mol} \mathrm{kg} \mathrm{g}^{-1}$ at $115 \mathrm{~m}$ depth (or at the isopycnal surface $26.61 \mathrm{~kg} \mathrm{~m}^{-3}$ ) compared to surrounding waters, which have a mean $( \pm 1$ standard deviation) oxygen content of $113( \pm 38) \mu \mathrm{mol} \mathrm{kg}{ }^{-1}$ at around $150 \mathrm{~m}$ depth or $26.60( \pm 0.32) \mathrm{kg} \mathrm{m}^{-3}$ during the mooring period between 2006 and 2014. Schütte et al. (2016a) showed that around $52 \%$ of the eddies in the ETNA represents CEs. They have a marginally smaller radius, rotate faster and have a shorter lifetime compared to the anticyclonic eddies, which is also shown in other observational studies of Chaigneau et al. (2009), Chelton et al. (2011), and theoretically suggested by Cushman-Roisin et al. (1990).

From January 2007 to March 2007 (Fig. 5b), an ACME passed the CVOO mooring position. The core of the westward propagating eddy passed about $13 \mathrm{~km}$ north of the mooring. The velocity field shows strong subsurface anticyclonic rotation at the depth of the core, i.e., between 80 and $100 \mathrm{~m}$. In contrast to "normal" anticyclonic eddies, the water mass in the core of an ACME is colder and less saline than the surrounding waters. The isopycnals above the core are elevated resulting in shallower MLs both resembling a cyclone. Beneath the core, the isopycnals are strongly depressed as in a normal anticyclone. Thus, dynamically this resembles a mode-water anticyclone, an eddy type which is well known from local single observations in al- 
Table 1. Available oxygen measurements below $40 \mu \mathrm{mol} \mathrm{kg}^{-1}$ in the ETNA. The * indicates recent observations which are not included in Fig. 4 due to not existent delayed time satellite products.

\begin{tabular}{|c|c|c|c|}
\hline & Time & $\begin{array}{c}\text { Minimum } \mathrm{O}_{2} \text { between } \\
0 \text { and } 200 \mathrm{~m}\end{array}$ & $\begin{array}{l}\text { Associated eddy } \\
\text { type }\end{array}$ \\
\hline \multicolumn{4}{|l|}{$\begin{array}{l}11 \text { ship cruises: } \\
\text { (81 profiles) }\end{array}$} \\
\hline Meteor 68/3 & Summer 2006 & 17 & $\mathrm{CE}$ \\
\hline L'Atalante GEOMAR 3 & Winter 2008 & 25 & ACME \\
\hline Meteor $80 / 2$ & Winter 2009 & 32 & ACME \\
\hline Meteor 83/1 & Winter 2010 & 20 & $\mathrm{ACME}$ \\
\hline Meteor 96 & Spring 2013 & 38 & ACME \\
\hline Meteor 97 & Summer 2013 & 28 & ACME \\
\hline Islandia & Spring 2014 & 10 & ACME \\
\hline Meteor 105 & Spring 2014 & 4 & ACME \\
\hline Meteor 116 & Spring 2015 & 17 & ACME* \\
\hline Meteor 119 & Autumn 2015 & 30 & $\mathrm{ACME}^{*}$ \\
\hline Maria S. Merian 49 & Winter 2015 & 35 & $\mathrm{CE}^{*}$ \\
\hline \multicolumn{4}{|l|}{$\begin{array}{l}9 \text { Argo floats: } \\
\text { ( } 24 \text { profiles) }\end{array}$} \\
\hline 6900632 & Autumn 2008 & 14 & $\mathrm{CE}$ \\
\hline 1900652 & Winter 2008 & 26 & ACME \\
\hline 1900650 & Summer 2009 & 27 & ACME \\
\hline 1901360 & Autumn 2014 & 34 & $\mathrm{CE}$ \\
\hline 1901361 & Autumn 2014 & 21 & $\mathrm{CE}$ \\
\hline 1901362 & Autumn 2014 & 26 & $\mathrm{CE}$ \\
\hline 1901363 & Autumn 2014 & 37 & $\mathrm{CE}$ \\
\hline 1901364 & Autumn 2014 & 24 & ACME \\
\hline 1901365 & Autumn 2014 & 24 & ACME \\
\hline \multicolumn{4}{|l|}{$\begin{array}{l}4 \text { gliders: } \\
\text { (32 profiles) }\end{array}$} \\
\hline IFM 11 & Spring 2010 & 19 & ACME \\
\hline IFM 05 & Summer 2013 & 9 & $\mathrm{CE}$ \\
\hline IFM 12 & Winter 2014 & 1 & ACME \\
\hline IFM 13 & Spring 2014 & 1 & ACME \\
\hline \multicolumn{4}{|l|}{$\begin{array}{l}9 \text { CVOO events: } \\
\text { ( } 36 \text { profiles) }\end{array}$} \\
\hline Optode at $127 \mathrm{~m}$ depth & Winter 2007 & 15 & ACME \\
\hline Optode at $79 \mathrm{~m}$ depth & Autumn 2008 & 38 & $\mathrm{CE}$ \\
\hline Optode at $54 \mathrm{~m}$ depth & Winter 2010 & 2 & ACME \\
\hline Optode at $53 \mathrm{~m}$ depth & Winter 2012 & 17 & ACME \\
\hline Optode at $53 \mathrm{~m}$ depth & Spring 2012 & 30 & $\mathrm{CE}$ \\
\hline Optode at $45 \mathrm{~m}$ depth & Summer 2013 & 29 & ACME \\
\hline Optode at $45 \mathrm{~m}$ depth & Winter 2013 & 9 & $\mathrm{CE}$ \\
\hline Optode at $43 \mathrm{~m}$ depth & Winter 2015 & 2 & $\mathrm{ACME}^{*}$ \\
\hline Optode at $43 \mathrm{~m}$ depth & Summer 2015 & 6 & ACME* \\
\hline$\sum 173$ profiles & & & $\sum 27$ different \\
\hline
\end{tabular}

most all ocean basins (globally: Kostianoy and Belkin, 1989; McWilliams, 1985 ("submesoscale coherent vortices"); in the North Atlantic: Riser et al., 1986; Zenk et al., 1991 and Bower et al., 1995; Richardson et al., 1989; Armi and Zenk,
1984 ("Meddies"); in the Mediterranean Sea: Tauper-Letage et al., 2003 ("Leddies"); in the North Sea: Van Aken et al., 1987; in the Baltic Sea: Zhurbas et al., 2004; in the Indian Ocean: Shapiro and Meschanov, 1991 ("Reddies"); in the 


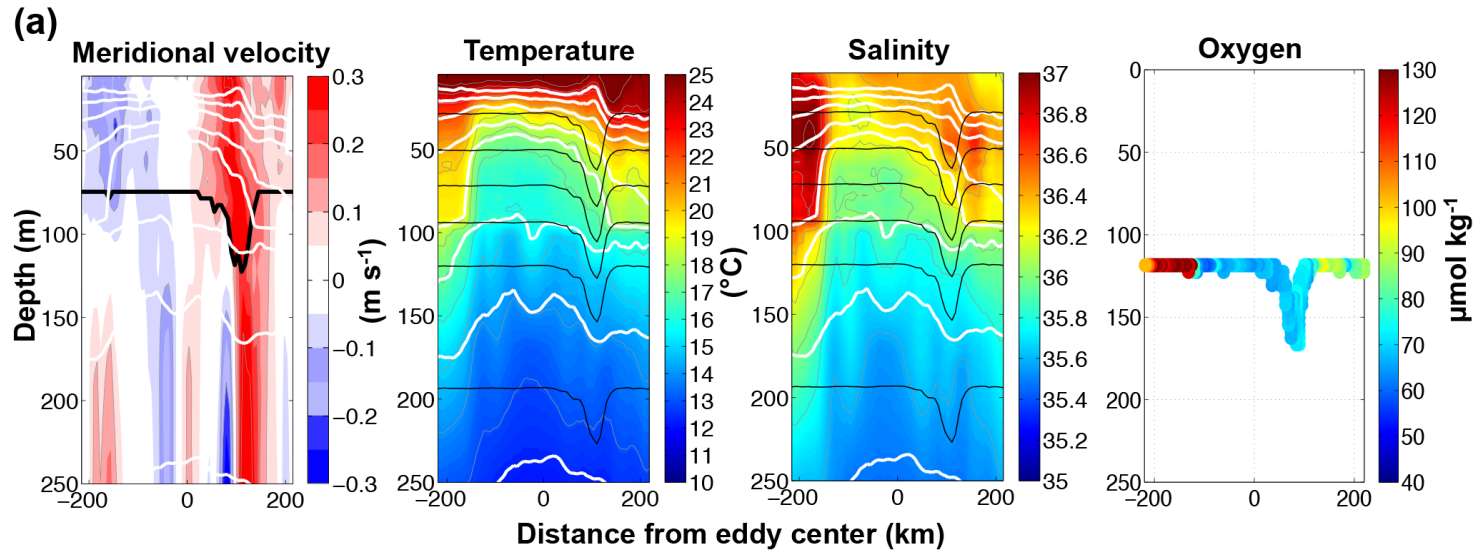

(b)
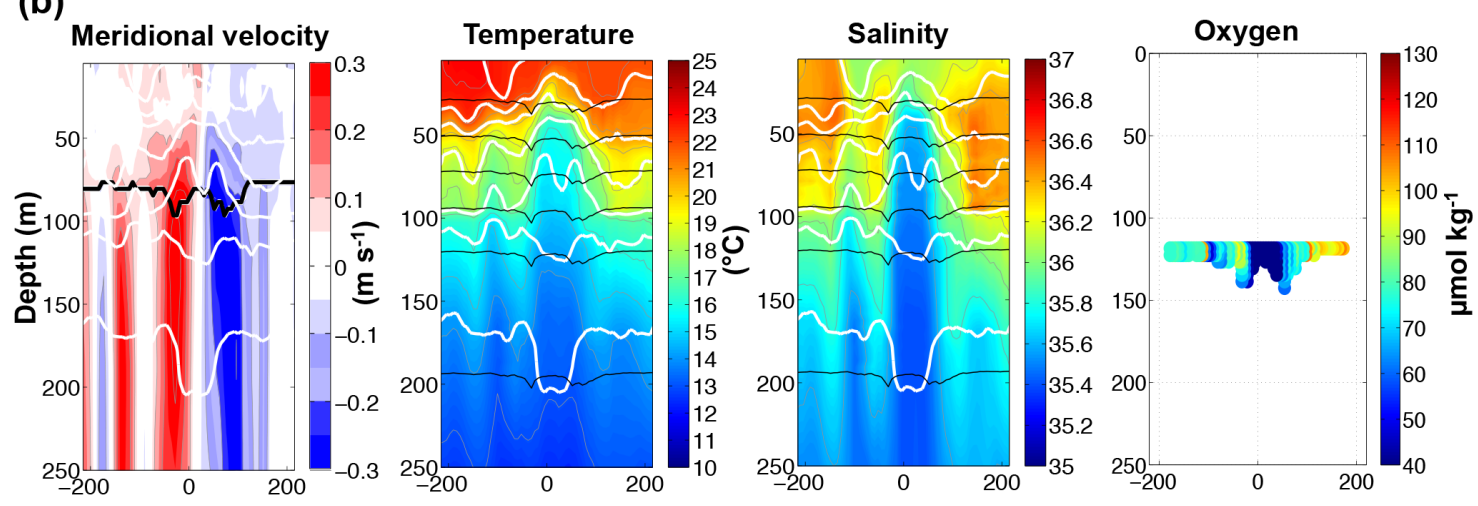

Figure 5. Meridional velocity, temperature, salinity and oxygen of an exemplary (a) CE and (b) ACME at the CVOO mooring. Both eddies passed the CVOO on a westward trajectory with the eddy center north of the mooring position (CE $20 \mathrm{~km}$, ACME $13 \mathrm{~km})$. The CE passed the CVOO from October to December 2006 and the ACME between January and March 2007. The thick black lines in the velocity plots indicate the position of an upward looking ADCP. Below that depth calculated geostrophic velocity is shown. The white lines represent density surfaces inside the eddies and the thin grey lines isolines of temperature and salinity, respectively. Thin black lines in the temperature and salinity plot mark the vertical position of the measuring devices. On the right a time series of oxygen is shown from the one sensor available at nominal $120 \mathrm{~m}$ depth.

North Pacific: Lukas and Santiago-Mandujano, 2001; Molemaker et al., 2015 ("Cuddies"); in the South Pacific: Stramma et al., 2013; Colas et al., 2012; Combes et al., 2015; Thomsen et al., 2015 and Nof et al., 2002 ("Teddies"); in the Arctic: D'Asaro, 1988; Oliver et al., 2008). For the majority of the observed mode-water-type eddies the depressed isopycnals in deeper water mask the elevated isopycnals in the shallow water in terms of geostrophic velocity, resulting in an anticyclonic surface rotation and a weak positive SLA (Gaube et al., 2014).

In contrast to most of the ACMEs reported, the CVOO ACME eddy core is located at very shallow depth, just beneath the ML. The oxygen content in the eddy's core recorded from the CVOO mooring is strongly decreased with values around $19 \mu \mathrm{mol} \mathrm{kg}{ }^{-1}$ at $123 \mathrm{~m}$ depth (or $26.50 \mathrm{~kg} \mathrm{~m}^{-3}$ ) compared to the surrounding waters (113 $\left.( \pm 38) \mu \mathrm{mol} \mathrm{kg}^{-1}\right)$. Within the entire time series, the CVOO mooring recorded the passage of several ACMEs with even lower oxygen concentrations (for more information see
Karstensen et al., 2015, or Table 1). Recent model studies suggest that ACMEs represent a non-negligible part of the worlds eddy field, particular in upwelling regions (Combes et al., 2015; Nagai et al., 2015). Schütte et al. (2016a) could show, based on observational data, that ACMEs represent around $9 \%$ of the eddy field in the ETNA. Their radii are in the order of the first baroclinic-mode Rossby radius of deformation and their eddy cores are well isolated (Schütte et al., 2016a).

\subsection{Combining in situ and satellite data for low-oxygen eddy detection in the ETNA}

Combining the location and time of in situ detection of lowoxygen eddies with the corresponding SLA satellite data reveals a clear link to the surface manifestation of mesoscale structures, CEs and ACMEs (Fig. 4). Composite surface signatures for SLA, SST and Chl from all anomalous lowoxygen eddies as identified in the in situ dataset are shown 
(a) SLA (ACME)

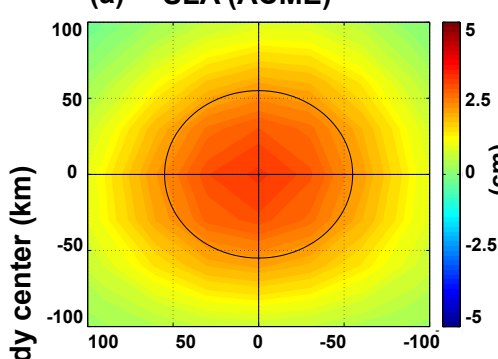

(b) SLA (Cyclone)

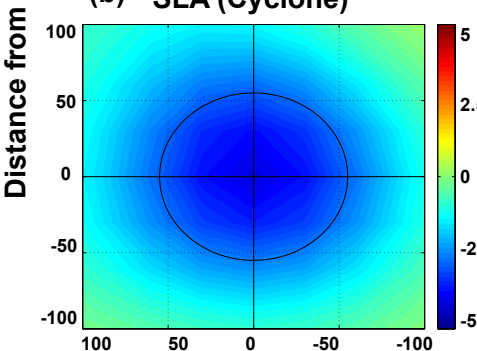

SST (ACME)

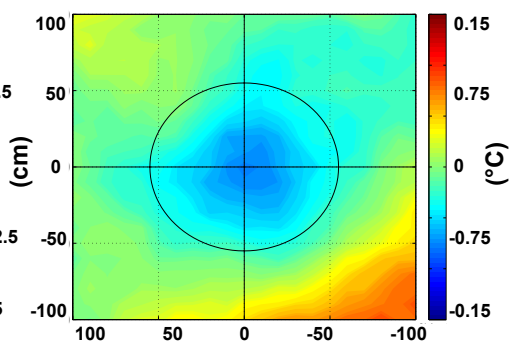

SST (Cyclone)

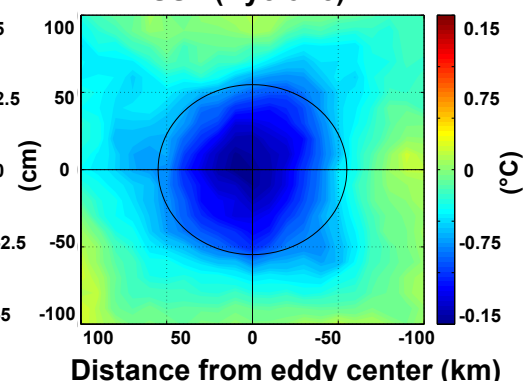

Chl (ACME)

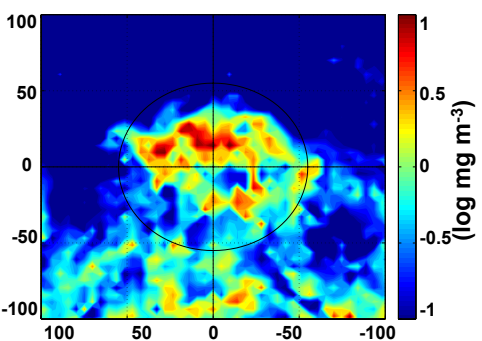

Chl (Cyclone)

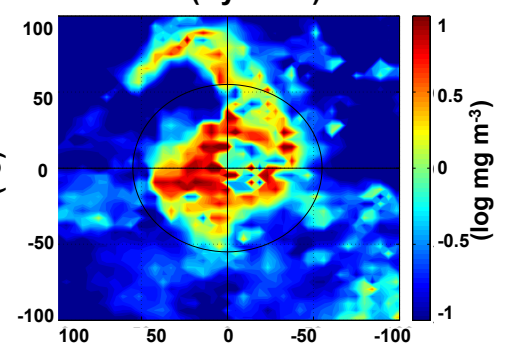

Figure 6. Composites of surface signature for SLA, SST and Chl from all detected low-oxygen eddies: (a) ACMEs and (b) CEs. The solid black cross marks the eddy center and the solid black circle the average radius. Due to significant cloud cover the number of Chl data are much less when compared to the SLA and SST data; thus there is more lateral structure.

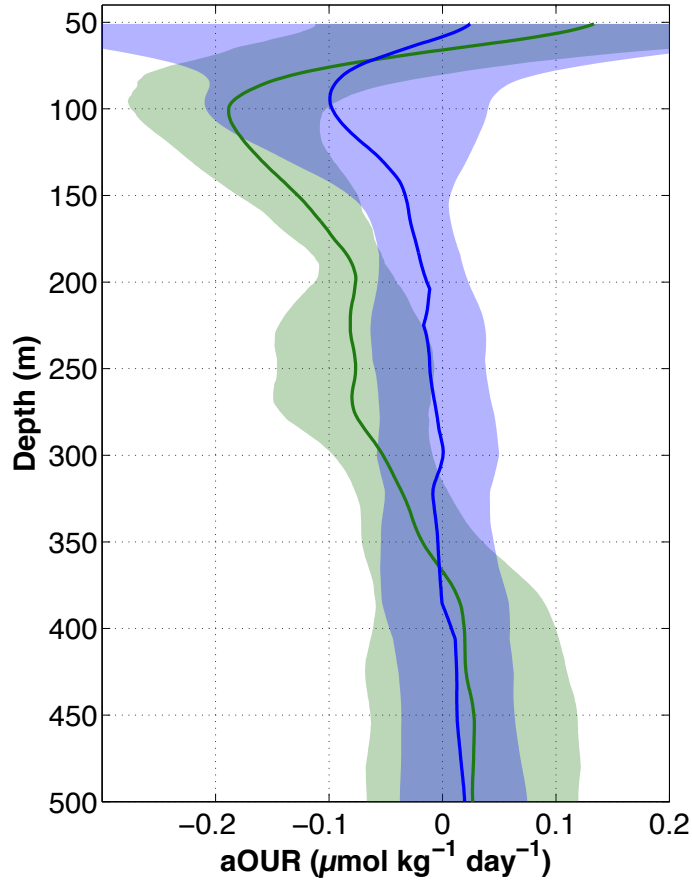

Figure 7. Depth profiles of a mean apparent oxygen utilization rate (aOUR, $\mu \mathrm{mol} \mathrm{kg} \mathrm{kg}^{-1} \mathrm{~d}^{-1}$ ) within CEs (blue) and ACMEs (green) in the ETNA with associated standard deviation (shaded area). Derived by using the propagation time of each eddy, an initial coastal oxygen profile and the assumption of linear oxygen consumption (based on depth layers). in Fig. 6. The ACME composites are based on 17 independent eddies and on 922 surface maps. The detected ACMEs are characterized by an elevation of SLA, which is associated with an anticyclonic rotation at the sea surface. The magnitude of the SLA displacement is moderate compared to normal anticyclones and CEs (Schütte et al., 2016a). More distinct differences to normal anticyclones are the cold-water anomaly and the elevated $\mathrm{Chl}$ concentrations in the eddy center of the ACMEs. Normal anticyclones are associated with elevated SST and reduced $\mathrm{Chl}$ concentrations. Through a combination of the different satellite products (SLA, SST, $\mathrm{SSS}$ ) it is possible to determine low-oxygen eddies from satellite data alone (further details of the ACME tracking and the average satellite surface signatures (SLA, SST, SSS) of all eddy types (CEs, anticyclones and ACMEs) identified in 19 years of satellite data in Schütte et al., 2016a).

The composite mean surface signature for low-oxygen CEs is based on 10 independent eddies and on 755 surface maps. The CEs are characterized by a negative SLA and SST anomaly. The observed negative SST anomaly of the low-oxygen $\mathrm{CEs}$ is twice as large (core value $\mathrm{CE}$ : -0.12 $( \pm 0.2)^{\circ} \mathrm{C}$; core value ACME: $\left.-0.06( \pm 0.2)^{\circ} \mathrm{C}\right)$ as the corresponding anomaly of the ACMEs. The Chl concentration in the eddy center is also higher for CEs compared to ACMEs (core value CE: $0.35( \pm 0.22) \log \mathrm{mg} \mathrm{m}^{-3}$; core value ACME: $\left.0.21( \pm 0.17) \log \mathrm{mg} \mathrm{m}^{-3}\right)$. Note that we only considered the measured low-oxygen ACMEs and CEs from Table 1 to derive the composites. 

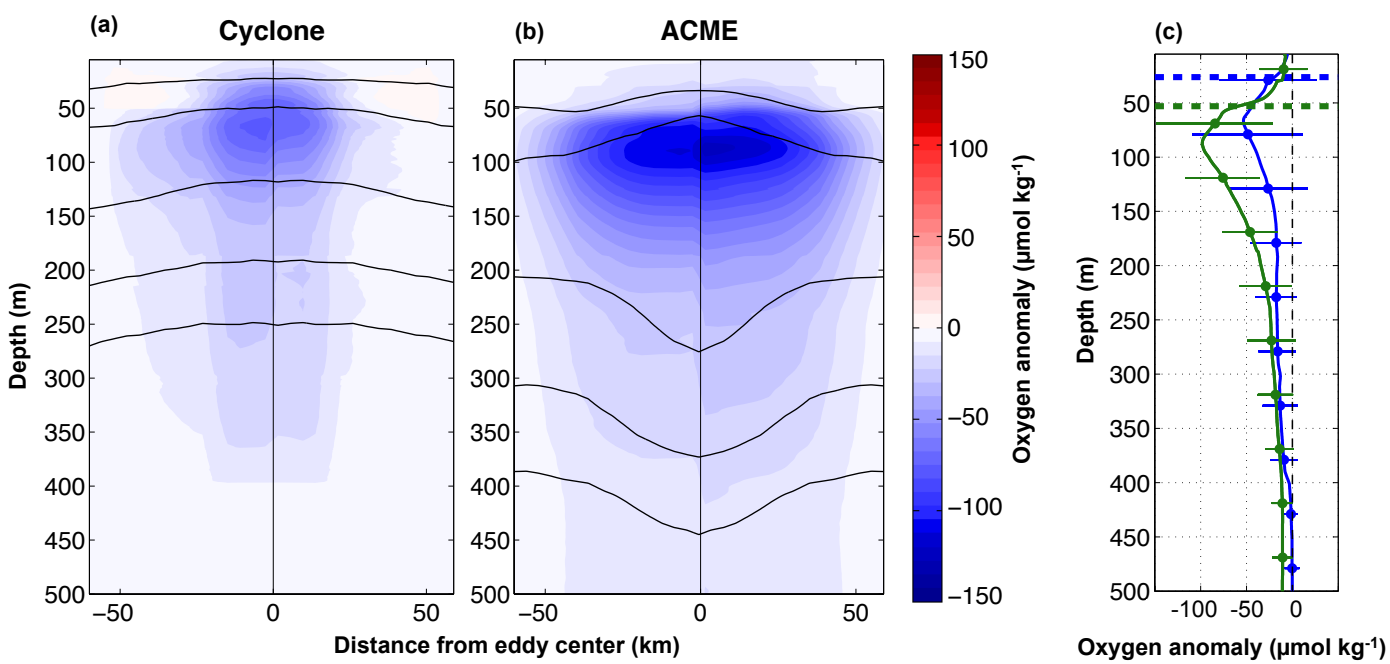

Figure 8. Vertical structure of oxygen from the composite (a) CE and (b) ACME in the ETNA presented as a half section across the eddies. The left side of both panels $(-60$ to $0 \mathrm{~km})$ is based on reconstructed and measured oxygen profiles whereas the right side $(0$ to $60 \mathrm{~km})$ is based on measured oxygen profiles only. Both methods are shown against the normalized radial distance. The blackb lines represents the density surfaces inside the eddies. (c) Mean profiles of the oxygen anomalies based on measured profiles only; green lines are associated with ACMEs and blue to CEs. Horizontal lines indicate the standard deviation of the oxygen anomaly at selected depths. The thick dashed lines indicates the mean ML within the different eddy types. The grey vertical dashed line represents zero oxygen anomaly.

Using the eddy-dependent surface signatures in SLA, SST and $\mathrm{Chl}$ the low-oxygen eddies could be tracked and an eddy trajectory could be derived (e.g., Fig. 4). All detected eddies were propagating westward into the open ocean. North of $12^{\circ} \mathrm{N}$, most of the eddies set off near the coast, whereas south of $12^{\circ} \mathrm{N}$ the eddies seem to be generated in the open ocean. Detected CEs have a tendency to deflect poleward on their way into the open ocean (Chelton et al., 2011), whereas ACMEs seem to have no meridional deflection. However, during their westward propagation the oxygen concentration within the low-oxygen eddy cores decreases with time. Using the propagation time and an initial coastal oxygen profile (Fig. 3b), a mean apparent oxygen utilization rate per day could be derived for all sampled eddies (Fig. 7). On average the oxygen concentration decreases by about $0.19 \pm 0.08 \mu \mathrm{mol} \mathrm{kg} \mathrm{d}^{-1} \mathrm{~d}^{-1}$ in the core of an isolated ACME but has no significant trend in the core of an isolated CE $\left(0.10 \pm 0.12 \mu \mathrm{mol} \mathrm{kg}^{-1} \mathrm{~d}^{-1}\right)$. This is in the range of recently published aOUR estimates for single observations of CEs (Karstensen et al., 2015) and ACMEs (Fiedler et al., 2016).

\subsection{Mean oxygen anomalies from low-oxygen eddies in the ETNA}

In Fig. 8 we compare the mean oxygen anomalies based purely on observations with those based on the extended profile database, including observed and reconstructed oxygen values (see Sect. 2.4). It shows the mean oxygen anomalies against the surrounding water for CE (Fig. 8a) and ACME (Fig. 8b) vs. depth and normalized radial distance. On the left side of each panel the anomaly is based on the observed and reconstructed oxygen values ( 736 oxygen profiles; 575 in CEs; 161 in ACMEs), whereas on the right side the anomaly is based only on the observed oxygen measurements (504 oxygen profiles; 395 in CEs; 109 in ACMEs). The distinct mean negative oxygen anomalies for CEs and ACMEs indicate the low-oxygen concentrations in the core of both eddy types compared to the surrounding water. The strongest oxygen anomalies are located in the upper water column, just beneath the ML. CEs feature maximum negative anomalies of around $-100 \mu \mathrm{mol} \mathrm{kg}{ }^{-1}$ at around $70 \mathrm{~m}$ depth in the eddy core, with a slightly more pronounced oxygen anomaly when including the reconstructed values (left side of Fig. 8) compared to the oxygen anomaly based purely on observation (right side of Fig. 8a). This is contrary for the ACME with stronger oxygen anomalies on the right part than on the left (Fig. 8b). Both methods deliver maximum negative anomalies of around $-120 \mu \mathrm{mol} \mathrm{kg}^{-1}$ at around $100 \mathrm{~m}$ depth in the ACME core. At that depth, the diameter of the mean oxygen anomaly is about $100 \mathrm{~km}$ for ACMEs and $70 \mathrm{~km}$ for CEs (the eddy core is defined here as the area of oxygen anomalies smaller than $-40 \mu \mathrm{mol} \mathrm{kg}{ }^{-1}$ ). Beneath $150 \mathrm{~m}$ depth, magnitude and diameter of the oxygen anomalies decrease rapidly for both eddy types. Figure $8 \mathrm{c}$ is based on both the in situ and reconstructed oxygen values and shows the horizontal mean oxygen anomaly profile of each eddy type against depth obtained by horizontally averaging the oxygen anomalies shown in Fig. 8a and b. The maximum anomalies are $-100 \mu \mathrm{mol} \mathrm{kg}-1$ at around $90 \mathrm{~m}$ for ACMEs and $-55 \mu \mathrm{mol} \mathrm{kg}-1$ at around $70 \mathrm{~m}$ for cyclones. Both eddy types have the highest oxygen variance directly beneath the 
ML (in the eddy core) or slightly above the eddy core. The oxygen anomaly (and associated variance) decreases rapidly with depth beneath the eddy core and is smaller than around $-10 \pm 10 \mu \mathrm{mol} \mathrm{kg}{ }^{-1}$ beneath $350 \mathrm{~m}$ for both eddy types.

\section{Discussion}

The pelagic zones of the ETNA are traditionally considered to be "hypoxic", with minimal oxygen concentrations of marginally below $40 \mu \mathrm{mol} \mathrm{kg}{ }^{-1}$ (Brandt et al., 2015; Karstensen et al., 2008; Stramma et al., 2009). This is also true for the upper $200 \mathrm{~m}$ (Fig. 1). However, single oxygen profiles taken from various observing platforms (ships, moorings, gliders, floats) with oxygen concentrations in the range of severe hypoxia $\left(<20 \mu \mathrm{mol} \mathrm{kg}{ }^{-1}\right)$ and even anoxia $\left(\sim 1 \mu \mathrm{mol} \mathrm{kg}{ }^{-1}\right)$ conditions and consequently below the canonical value of $40 \mu \mathrm{mol} \mathrm{kg}{ }^{-1}$ (Stramma et al., 2008) are found in a surprisingly high number (in total 180 profiles) in the ETNA. In the current analysis we could associate observations of low-oxygen profiles with 27 independent mesoscale eddies (10 CEs and 17 ACMEs). Mesoscale eddies are defined as coherent, nonlinear structures with a lifetime of several weeks to more than a year and radii larger than the first baroclinic-mode Rossby radius of deformation (Chelton et al., 2007). In reference to the surrounding water, the eddies carry a negative oxygen anomaly which is most pronounced right beneath the ML. The oxygen anomaly is attributed to both an elevated primary production in the surface layers of the eddies (documented by positive chlorophyll anomalies estimated from satellite observations, Fig. 6) and the subsequent respiration of organic material (Fiedler et al., 2016), as well as the dynamically induced isolation of the eddies with respect to lateral oxygen resupply (Fiedler et al., 2016; Karstensen et al., 2015). In contrast to the transport of heat or salt with ocean eddies, the oxygen anomaly intensified with the time the eddy existed (eddy age). The oxygen-depleted eddy cores are associated with either CEs or ACMEs. In the ETNA both eddy types have in common that in their center the ML base rises towards shallow depth (50 to $100 \mathrm{~m}$ ), which in turn favors biological productivity in the euphotic zone (Falkowski et al., 1991; McGillicuddy et al., 1998). In addition, an enhanced vertical flux of nutrients within or at the periphery of the eddies due to submesoscale instabilities is expected to occur (Brannigan et al., 2015; Karstensen et al., 2016; Lévy et al., 2012; Martin and Richards, 2001; Omand et al., 2015).

As a consequence the eddies establish a specific ecosystem of high primary production, particle load and degradation processes, and even unexpected nitrogen loss processes (Löscher et al., 2015). The combination of high productivity and low-oxygen supply resembles the process of "deadzone" formation, known from other aquatic systems. As for other aquatic systems, specific threats to the ecosystem of the
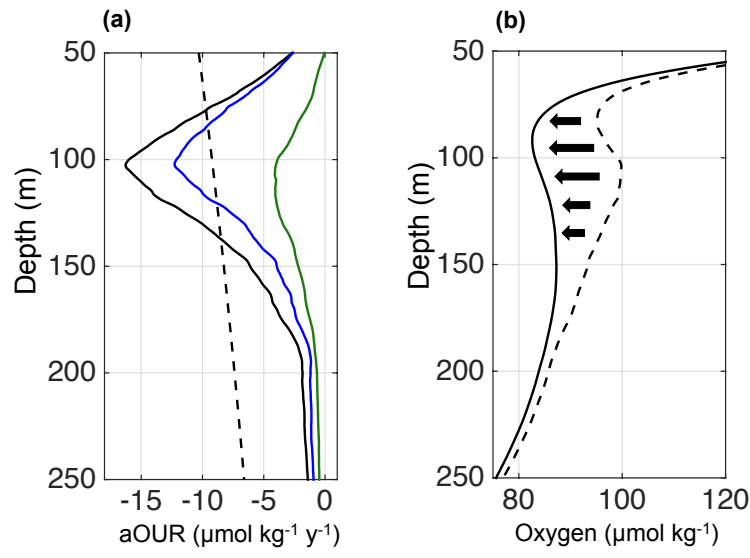

Figure 9. (a) Depth profile of the apparent oxygen utilization rate (aOUR, $\mu \mathrm{mol} \mathrm{kg}^{-1} \mathrm{yr}^{-1}$ ) for the Atlantic as published from Karstensen et al. (2008; dashed black line). The oxygen consumption profile due to low-oxygen eddies referenced for the SOMZ region (solid black line) and the separation into CEs (blue) and ACMEs (green). The solid black line in (b) represents the observed mean vertical oxygen profile of all profiles within the SOMZ against depth, whereas the dashed black line represents the theoretical vertical oxygen profile in the SOMZ without the dispersion of lowoxygen eddies. Naturally due to the dispersion of negative oxygen anomalies, the observed values (black line) are lower than the theoretical oxygen concentrations in the SOMZ without eddies (dashed black line). The impact of the dispersion of low-oxygen eddies on the oxygen budget in the depth of the shallow oxygen minimum zone is also indicated by the thick black arrows.

eddies are observed such as the interruption of the diurnal migration of zooplankters (Hauss et al., 2016).

We observed low-oxygen cores only in ACMEs (also known as submesoscale coherent vortices in D'Asaro, 1988, and McWilliams, 1985, or intra-thermocline eddies in Kostianoy and Belkin, 1989) and CEs but not in normal anticyclonic rotating eddies. In fact the ML base in normal anticyclonic eddies is deeper than the surroundings, bending downward towards the eddy center as a consequence of the anticyclonic rotation. Therefore the normal anticyclones create a positive oxygen anomalies when using depth levels as a reference. However, when using density surfaces as a reference, the anomalies disappear. Moreover, normal anticyclonic eddies have been found to transport warm and salty anomalies (Schütte et al., 2016a) along with the positive oxygen anomaly, which is very different from the ACMEs (and CEs) with a low-oxygen core.

The ETNA is expected to have a rather low population of long-lived eddies (Chaigneau et al., 2009; Chelton et al., 2011), we could identify 234 CEs and 18 ACMEs per year in the ETNA with a radius $>45 \mathrm{~km}$ and a tracking time of more than 3 weeks. For the eddy detection we used an algorithm based on the combination of the Okubo-Weiß method and a modified version of the geometric approach from Nencioli et al. (2010) with an adjusted tracking for the ETNA (for more 
information see Schütte et al., 2016a). Schütte et al. (2016a) found an eddy-type-dependent connection between SLA and SST (and SSS) signatures for the ETNA that allowed a detection (and subsequently closer examination) of ACMEs. Because of weaker SLA signatures, the tracking of ACMEs is rather difficult due to the small signal-to-noise ratio (not the case for the CEs) and automatic tracking algorithms may fail in many cases. Note that all tracks of ACMEs and CEs shown in Fig. 4 were visually verified. Similar to Schütte et al. (2016a), we derived "dead-zone" eddies surface composites for SST, SSS (not shown here) and Chl (Fig. 6). It revealed that the existence of an ACMEs is very associated with low SST (and SSS) but also with high Chl (see also single maps in Karstensen et al., 2015). Analyzing jointly SLA, SST and Chl maps we found that ACMEs represent a nonnegligible part of the eddy field (32\% normal anticyclones, $52 \%$ CEs, $9 \%$ ACMEs; Schütte et al., 2016a).

It has been shown (Fig. 4) that the low-oxygen eddies in the ETNA could be separated into two different regimes: north and south of $12^{\circ} \mathrm{N}$. The eddies north of $12^{\circ} \mathrm{N}$ are generally generated along the coast and in particular close to the headlands along the coast. Schütte et al. (2016a) suggested that CEs and normal anticyclones north of $12^{\circ} \mathrm{N}$ are mainly generated from instabilities of the northward directed alongshore Mauritania Current (MC), whereas the ACMEs are most likely generated by instabilities the Poleward Undercurrent (PUC). However, the detailed generation processes need to be further investigated. The low-oxygen eddies south of $12^{\circ} \mathrm{N}$ do not originate from a coastal boundary upwelling system. Following the trajectories it seems that the eddies are generated in the open ocean between 5 and $7^{\circ} \mathrm{N}$. In general, the occurrence of oxygen-depleted eddies south of $12^{\circ} \mathrm{N}$ is rather astonishing, as due to the smaller Coriolis parameter closer to the Equator the southern eddies should be more short-lived and less isolated compared to eddies further north. In addition, the generation mechanism of the southern eddies is not obvious. The eddy generation could be related to the presence of strong tropical instabilities in that region (Menkes et al., 2002; von Schuckmann et al., 2008). However, in particular the generation of ACMEs is complex and has been subject of scientific interest for several decades already (D'Asaro, 1988; McWilliams, 1985). The low stratification of the eddy core cannot be explained by pure adiabatic vortex stretching alone as this mechanism will result in cyclonic vorticity, assuming that $f$ dominates the relative vorticity. Accordingly, the low stratification in the eddy core must be the result of some kind of preconditioning induced by for example upwelling, deep convection (Oliver et al., 2008) or diapycnal mixing near the surface or close to boundaries (D'Asaro, 1988) before eddy generation takes place (McWilliams, 1985). D'Asaro (1988), Molemaker et al. (2015) and Thomsen et al. (2015) highlight the importance of flow separation associated with headlands and sharp topographical variations for the generation of ACMEs. This notion is supported by the fact that low potential vorticity signals are usually observed in the ACMEs (D'Asaro, 1988; McWilliams, 1985; Molemaker et al., 2015; Thomas, 2008). The low potential vorticity values suggest that the eddy has been generated near the coast as - at least in the tropical latitudes - such low potential vorticity values are rarely observed in the open ocean. These theories seem to be well suitable for the ACME generation north of $12^{\circ} \mathrm{N}$ but do not entirely explain the occurrence of ACMEs south of $12^{\circ} \mathrm{N}$. However, more research on this topic is required.

Because we expect "northern" and "southern" eddies to have different generation mechanisms and locations and because they have different characteristics we discuss them separately. The core of the eddies generated north of $12^{\circ} \mathrm{N}$ is characterized by less saline and cold SACW (Schütte et al., 2016a) and thereby forms a strong hydrographic anomaly against the background field. In contrast, the core of the eddies generated south of $12^{\circ} \mathrm{N}$ does not show any significant hydrographic anomalies. However, a low-oxygen core in eddies is observed in both regions, indicating that the combination of the isolation of the eddy core and the high productivity in the eddy surface waters also occurs in both regions. The oxygen content decreases on average by about $0.19 \pm 0.08 \mu \mathrm{mol} \mathrm{kg}^{-1} \mathrm{~d}^{-1}$ in an ACME and by about $0.10 \pm 0.12 \mu \mathrm{mol} \mathrm{kg}^{-1} \mathrm{~d}^{-1}$ in an CE, based on 504 oxygen measurements in CEs and ACMEs. Note that these apparent oxygen utilization rates (aOUR) are in the range of recently published aOUR estimates for CEs (Karstensen et al., 2015) and ACMEs (Fiedler et al., 2016), which are based on single measurements in "dead-zone" eddies. In particular for CEs we take that as an indication that no significant trend in aOUR exists. An important point regarding the method and the associated inaccuracies in deriving the aOURs is the initial coastal oxygen concentration, which is highly variable in coastal upwelling regions (Thomsen et al., 2015). In addition one should mention that the relative magnitude of eddy-dependent vertical nutrient flux, primary productivity and associated oxygen consumption or nitrogen fixation/denitrification in the eddy cores strongly varies among different eddies because of differences in the initial water mass in the eddies' core, the eddies' age and isolation and the experienced external forcing (in particular wind stress and dust/iron input).

However, the mean oxygen profiles from the eastern boundary and inside of all CEs and ACMEs (Fig. 3b) indicate no pronounced oxygen difference beneath $250 \mathrm{~m}$ depth. The largest anomalies have been observed in the eddy cores at around $100 \mathrm{~m}$ depth (Fig. 8). As a result of the dynamic structure, the core water mass anomalies of the ACMEs are more pronounced than the one of the CE (Karstensen et al., 2016) and consequently the oxygen anomalies are stronger. This is supported by the differences in the oxygen anomaly based on the measured plus reconstructed and the measured oxygen values. The reconstruction of oxygen values assumes a complete isolation of the eddy core. The left side of Fig. 8a, which includes the reconstructed oxygen values, features a 
larger oxygen anomaly than the right side based on measured oxygen values only. Consequently the CEs are probably not completely isolated and the evolving oxygen anomaly is affected by some lateral flux of oxygen. In contrast, the oxygen anomaly of ACMEs (Fig. 8b) is smaller for the reconstruction than for the measured oxygen values. This suggests that the ACMEs are more effectively isolated, resulting in enhanced apparent consumption in the ACME core. However, another source of error in the reconstructed oxygen values is the assumption of a linear decrease of oxygen with time. All observed CEs or ACMEs contain a negative oxygen anomaly, partly because they transport water with initial low-oxygen concentrations and additionally because the oxygen consumption in the eddies is more intense then in the surrounding waters (Karstensen et al., 2015; Fiedler et al., 2016). D’Asaro (1988), Molemaker et al. (2015) and Thomsen et al. (2015) argued that the core waters of ACMEs generated near the coast originate to a large extent from the bottom boundary layer at the continental slopes. At the shelf off northwestern Africa, low-oxygen concentrations (around $30 \mu \mathrm{mol} \mathrm{kg}{ }^{-1}$ ) in the depth range between 50 and $150 \mathrm{~m}$ could occasionally locally identified (M. Dengler, personal communication, 2016). Consequently it is certainly possible that the eddies have initially low-oxygen concentrations in their cores. This is not the case for the short-lived southern eddies, which seem to be generated in the open ocean. It would suggest that, to achieve similarly strong negative oxygen anomalies, the oxygen consumption in the eddies south of $12^{\circ} \mathrm{N}$ must be even stronger than in the ACMEs further north. Pronounced productivity patterns in tropical instability waves and vortices have been reported in the past (Menkes et al., 2002) but were not connected to low-oxygen eddies before.

In the following, an estimate of the contribution of the negative oxygen anomalies of low-oxygen eddies to the oxygen distribution of the SOMZ is presented. The satellite-based eddy tracking reveals that on average each year 14 (2) CEs (ACMEs) are propagating from the upwelling system near the coast into the SOMZ and dissipate there. By deriving the oxygen anomaly on density surfaces an oxygen loss profile due to low-oxygen eddies in the SOMZ is derived (Fig. 9). Note that due to the lower oxygen values within the eddies compared to the surrounding waters in the SOMZ, the release of negative oxygen anomalies to the surrounding waters is equivalent to a local (eddy volume) enhancement of the oxygen utilization by $-7.4(-2.4) \mu \mathrm{mol} \mathrm{kg} \mathrm{kg}^{-1} \mathrm{yr}^{-1}$ for CEs (ACMEs) for the depth range of the shallow oxygen minimum in the SOMZ, i.e., 50 to $150 \mathrm{~m}$ depth. Instead of describing the effect of the low-oxygen eddies on the oxygen consumption an equivalent view is to consider a box model approach for the SOMZ. The basis of this box model is the mixing of high-oxygen waters (the background conditions) with low-oxygen waters (the low-oxygen eddies). The average oxygen concentrations within the eddies in the considered depth range, i.e., 50 to $150 \mathrm{~m}$, are 73 (66) $\mu \mathrm{mol} \mathrm{kg} \mathrm{kg}^{-1}$ for CEs (ACMEs). The average oxygen concentration of the background field averaged over the same depth range (between 50 and $150 \mathrm{~m}$ ) derived from the MIMOC climatology (Schmidtko et al., 2013) is $118 \mu \mathrm{mol} \mathrm{kg}{ }^{-1}$. This climatological value includes the contribution of low-oxygen eddies. If we now consider the respective oxygen concentrations and volumes of the SOMZ and the eddies (multiplied by their frequency of occurrence per year), we are able to calculate the theoretical background oxygen concentration for the SOMZ without eddies to be $125 \mu \mathrm{mol} \mathrm{kg}{ }^{-1}$. Naturally due to the dispersion of negative oxygen anomalies, the oxygen concentrations in the SOMZ without eddies must be higher than the observed climatological values. Attributing the difference of these oxygen concentrations, on the one hand in the SOMZ without eddies $\left(125 \mu \mathrm{mol} \mathrm{kg}{ }^{-1}\right)$ and on the other hand the observed climatological values in the SOMZ with eddies $\left(118 \mu \mathrm{mol} \mathrm{kg}{ }^{-1}\right)$, solely to the decrease induced by the dispersion of eddies, we find that an equivalent reduction of around $7 \mu \mathrm{mol} \mathrm{kg} \mathrm{kg}^{-1}$ of the observed climatological oxygen concentration in the SOMZ box. To visualize that a depth profile of oxygen in the SOMZ without the dispersion of low-oxygen eddies is equally derived and compared to the observed oxygen profile in the SOMZ (Fig. 9b). Consequently, the oxygen consumption in this region is a mixture of the large-scale metabolism in the open ocean (Karstensen et al., 2008) and the enhanced metabolism in low-oxygen eddies (Karstensen et al., 2016; Fiedler et al., 2016). Note that a small compensating effect, for example due to diapycnal oxygen fluxes in normal anticyclones, can probably be expected. However, our estimates should be considered as a lower limit for the contribution of ACMES because of the problem in detecting and tracking ACMEs (weak SLA anomaly) and because of the assumption of zero lateral ventilation within the eddies. Moreover, we identified a few occurrences of ACMEs based on shipboard ADCP as well as hydrographic measurements (e.g., during the research cruises of Ron Brown 2009 and Meteor 119) that did not have a significant SLA signature. In addition, only eddies are considered which could be followed with tracking algorithms directly from the coast into the transition zone and have a radius greater than $45 \mathrm{~km}$ and a lifetime of more than 21 days.

Although a reduction of $7 \mu \mathrm{mol} \mathrm{kg}{ }^{-1}$ seems to be small, one may note that the peak difference is a reduction of $16 \mu \mathrm{mol} \mathrm{kg} \mathrm{kg}^{-1}$ at $100 \mathrm{~m}$ depth (Fig. 9) in the core depth of the shallow oxygen minimum zone in the ETNA. The additional respiration due to the presence of low-oxygen eddies can be important as well in numerical simulations, where up to now only the large-scale consumption is taken into account. In turn it is important to investigate the eddy occurrence and eddy cycling in numerical simulation of the OMZ given they have a sufficient resolution.

Our results question the assumption that the oxygen consumption is determined by the metabolism of the large-scale community alone. The observations presented here suggest 
instead that also hot spots of locally enhanced consumption may possibly need to be considered in the future.

\section{Conclusions}

In this study, we investigated the vertical structure of oxygendepleted eddies in the ETNA based on satellite (a combination of SLA and SST) and in situ oxygen and hydrography data (ship data, mooring data, profiling floats, underwater glider). We frequently detected oxygen concentrations below the canonical value of $40 \mu \mathrm{mol} \mathrm{kg}^{-1}$ within the ETNA that are associated with CEs and ACMEs. Lowest oxygen concentration in these eddies was observed at shallow depth, just underneath the ML between 50 and $150 \mathrm{~m}$. Both CEs and ACMEs are characterized by a positive $\mathrm{Chl}$ anomaly suggesting enhanced productivity in the eddy surface water. Respiration of the organic material, in combination with sluggish lateral oxygen fluxes across the eddy boundaries, most likely creates the low-oxygen core, a process that resembles the creation of "dead zones" but in the open ocean (Karstensen et al., 2015). Oxygen concentrations are found to decrease in the eddy cores during the westward propagation from their generation region along the West African coast into the open ocean. Our assessment reveals that 234 CEs (18 ACMEs) are generated each year (mostly on the eastern boundary) in the ETNA and can be tracked longer than 3 weeks (considered here as the timescale for coherent eddies). On average the oxygen concentration in the core of coherent CEs (ACMEs) decreases by about $0.10(0.19) \pm 0.12(0.08) \mu \mathrm{mol} \mathrm{kg}^{-1} \mathrm{~d}^{-1}$. Beside the eddies originating in generation regions along the West African coast, we observe low-oxygen eddies (primarily ACMEs) relatively close to the Equator, south of $12^{\circ} \mathrm{N}$. These eddies may be generated from flow instability processes occurring during the formation of tropical instability waves. However, both types of eddies (north of $12^{\circ} \mathrm{N}$ and south of $12^{\circ} \mathrm{N}$ ) contain their minimum oxygen concentration in the depth range where a shallow oxygen minimum is found in the ETNA. A simple box model approach on the basis of mixing ratios of high-oxygen waters with low-oxygen waters in the SOMZ reveals that a mean reduction of around $7 \mu \mathrm{mol} \mathrm{kg}^{-1}$ (peak reduction is $16 \mu \mathrm{mol} \mathrm{kg}^{-1}$ at $100 \mathrm{~m}$ depth) of the observed oxygen in the shallow oxygen minimum zone is explainable due to the dispersion of low-oxygen eddies. This value, though, is very likely underestimated due to difficulties in identifying and tracking of ACMEs. The additional consumption within these low-oxygen eddies represents a substantial part of the total consumption in the open ETNA and might be partly responsible for the formation and extent of the shallow oxygen minimum. Given the impact of ACMEs on the oxygen budget in the ETNA, a further distinction into the two types of anticyclonic eddies in global (Chelton et al., 2011; Zhang et al., 2013) as well as regional eddy assessments is necessary, particular in eastern boundary upwelling systems.

\section{Data availability}

The used satellite data SLA, SST and Chl can be freely downloaded at http://www.aviso.altimetry.fr/en/ data/products (CMEMS, 2016), http://www.remss.com/ measurements/sea-surface-temperature/ (REMSS, 2016) and http://oceancolor.gsfc.nasa.gov (NASA, 2016), respectively. The Argo float data are freely available at http: //www.argodatamgt.org/Access-to-data/Argo-data-selection (Argo Data Management Team, 2016) and the assembled shipboard measurements; shipboard CTD, glider and CVOO mooring data used in this paper are available at https://doi.pangaea.de/10.1594/PANGAEA.860778 (Schütte et al., 2016b).

Acknowledgements. This study was funded by the Deutsche Bundesministerium für Bildung und Forschung (BMBF) as part of the project AWA (01DG12073E), by the Deutsche Forschungsgemeinschaft through the Collaborative Research Centre "SFB 754" and several research cruises with RV Meteor, RV Maria S. Merian, Ronald H. Brown and RV L'Atalante, and furthermore by the Cluster of Excellence "The Future Ocean" (CP1341), the project "EddyHunt" (CP1341) and the BMBF project SOPRAN (03F0611A and 03F0662A). The CVOO mooring is part of the OceanSITES mooring network. The captains and the crew as well as all chief scientists and scientists of the research vessels and our technical group for their help with the fieldwork deserve special thanks. Furthermore the authors thank Tim Fischer for continuing support and discussion and Rebecca Hummels for proof-reading and for assisting in improving this paper.

The Argo data used in this study were collected and made freely available by the International Argo Program and the national programs that contribute to it (http://www.argo.ucsd.edu (Argo, 2016), http://argo.jcommops.org). The Argo Program is part of the Global Ocean Observing System. The Ssalto/Duacs altimeter products were produced and distributed by the Copernicus Marine and Environment Monitoring Service (CMEMS, 2016; http://marine.copernicus.eu). The microwave OI SST data are produced by Remote Sensing Systems and sponsored by National Oceanographic Partnership Program (NOPP), the NASA Earth Science Physical Oceanography Program and the NASA MEaSUREs DISCOVER Project. Data are available at www.remss.com. The chlorophyll $a$ version 6 is a remote dataset from the NASA Ocean Biology Processing Group (OBPG). The OBPG is the official NASA data center that archives and distributes ocean color data (http://oceancolor.gsfc.nasa.gov).

Edited by: D. Gilbert

Reviewed by: two anonymous referees 


\section{References}

Altabet, M. A., Ryabenko, E., Stramma, L., Wallace, D. W. R., Frank, M., Grasse, P., and Lavik, G.: An eddy-stimulated hotspot for fixed nitrogen-loss from the Peru oxygen minimum zone, Biogeosciences, 9, 4897-4908, doi:10.5194/bg-9-48972012, 2012.

Argo Data Management Team: Argo float data, available at: http: //doi.org/10.17882/42182\#42349, last access: 1 January 2016.

Armi, L. and Zenk, W.: Large Lenses of Highly Saline Mediterranean Water, J. Phys. Oceanogr., 14, 1560-1576, 1984.

Bakun, A.: Global Climate Change and Intensification of Coastal Ocean Upwelling, Science, 247, 198-201, 1990.

Bower, A. S., Armi, L., and Ambar, I.: Direct evidence of meddy formation off the southwestern coast of Portugal, Deep-Sea Res. Pt. I, 42, 1621-1630, 1995.

Brandt, P., Bange, H. W., Banyte, D., Dengler, M., Didwischus, S.-H., Fischer, T., Greatbatch, R. J., Hahn, J., Kanzow, T., Karstensen, J., Körtzinger, A., Krahmann, G., Schmidtko, S., Stramma, L., Tanhua, T., and Visbeck, M.: On the role of circulation and mixing in the ventilation of oxygen minimum zones with a focus on the eastern tropical North Atlantic, Biogeosciences, 12, 489-512, doi:10.5194/bg-12-489-2015, 2015.

Brannigan, L., Marshall, D. P., Naveira-Garabato, A., and Nurser, A. J. G.: The seasonal cycle of submesoscale flows, Ocean Model., 92, 69-84, 2015.

Capet, X., McWilliams, J. C., Mokemaker, M. J., and Shchepetkin, A. F.: Mesoscale to submesoscale transition in the California current system, Part I: Flow structure, eddy flux, and observational tests, J. Phys. Oceanogr., 38, 29-43, 2008.

Chaigneau, A., Eldin, G., and Dewitte, B.: Eddy activity in the four major upwelling systems from satellite altimetry (1992-2007), Prog. Oceanogr., 83, 117-123, 2009.

Chavez, F. P. and Messié, M.: A comparison of Eastern Boundary Upwelling Ecosystems, Prog. Oceanogr., 83, 80-96, 2009.

Chelton, D. B., Schlax, M. G., and Samelson, R. M.: Global observations of nonlinear mesoscale eddies, Prog. Oceanogr., 91, 167-216, 2011.

Chelton, D. B., Schlax, M. G., Samelson, R. M., and de Szoeke, R. A.: Global observations of large oceanic eddies, Geophys. Res. Lett., 34, L15606, doi:10.1029/2007GL030812, 2007.

CMEMS: Copernicus Marine and Environment Monitoring Service, Sea Level Anomaly, available at: http://marine.copernicus. eu, last access: 5 January 2016

Colas, F., McWilliams, J. C., Capet, X., and Kurian, J.: Heat balance and eddies in the Peru-Chile current system, Clim. Dynam., 39, 509-529, 2012.

Combes, V., Hormazabal, S., and Di Lorenzo, E.: Interannual variability of the subsurface eddy field in the Southeast Pacific, J. Geophys. Res.-Oceans, 120, 4907-4924, 2015.

Correa-Ramirez, M. A., Hormazabal, S., and Yuras, G.: Mesoscale eddies and high chlorophyll concentrations off central Chile $\left(29^{\circ}-39^{\circ} \mathrm{S}\right)$, Geophys. Res. Lett., 34, L12604, doi:10.1029/2007GL029541, 2007.

Cushman-Roisin, B., Tang, B., and Chassignet, E. P.: Westward Motion of Mesoscale Eddies, J. Phys. Oceanogr., 20, 758-768, 1990.

D'Asaro, E. A.: Generation of Submesoscale Vortices - a New Mechanism, J. Geophys. Res.-Oceans, 93, 6685-6693, 1988.
Falkowski, P. G., Ziemann, D., Kolber, Z., and Bienfang, P. K.: Role of Eddy Pumping in Enhancing Primary Production in the Ocean, Nature, 352, 55-58, 1991.

Fiedler, B., Grundle, D. S., Schütte, F., Karstensen, J., Löscher, C. R., Hauss, H., Wagner, H., Loginova, A., Kiko, R., Silva, P., Tanhua, T., and Körtzinger, A.: Oxygen utilization and downward carbon flux in an oxygen-depleted eddy in the eastern tropical North Atlantic, Biogeosciences, 13, 5633-5647, doi:10.5194/bg13-5633-2016, 2016.

Fischer, G., Karstensen, J., Romero, O., Baumann, K.-H., Donner, B., Hefter, J., Mollenhauer, G., Iversen, M., Fiedler, B., Monteiro, I., and Körtzinger, A.: Bathypelagic particle flux signatures from a suboxic eddy in the oligotrophic tropical North Atlantic: production, sedimentation and preservation, Biogeosciences, 13 , 3203-3223, doi:10.5194/bg-13-3203-2016, 2016.

Gaube, P., Chelton, D. B., Samelson, R. M., Schlax, M. G., and O'Neill, L. W.: Satellite Observations of Mesoscale EddyInduced Ekman Pumping, J. Phys. Oceanogr., 45, 104-132, 2014.

Gruber, N., Lachkar, Z., Frenzel, H., Marchesiello, P., Munnich, M., McWilliams, J. C., Nagai, T., and Plattner, G.-K.: Eddy-induced reduction of biological production in eastern boundary upwelling systems, Nat. Geosci., 4, 787-792, 2011.

Hahn, J., Brandt, P., Greatbatch, R. J., Krahmann, G., and Körtzinger, A.: Oxygen variance and meridional oxygen supply in the Tropical North East Atlantic oxygen minimum zone, Clim. Dynam., 43, 1-26, doi:10.1007/s00382-014-2065-0, 2014.

Hauss, H., Christiansen, S., Schütte, F., Kiko, R., Edvam Lima, M., Rodrigues, E., Karstensen, J., Löscher, C. R., Körtzinger, A., and Fiedler, B.: Dead zone or oasis in the open ocean? Zooplankton distribution and migration in low-oxygen modewater eddies, Biogeosciences, 13, 1977-1989, doi:10.5194/bg-13-1977-2016, 2016.

Hood, E. M. C., Sabine, L., and Sloyan, B. M.: The GO-SHIP repeat hydrography manual: A collection of expert reports and guidelines, IOCCP Rep. 14, 2010.

Karstensen, J., Fiedler, B., Schütte, F., Brandt, P., Körtzinger, A., Fischer, G., Zantopp, R., Hahn, J., Visbeck, M., and Wallace, D.: Open ocean dead zones in the tropical North Atlantic Ocean, Biogeosciences, 12, 2597-2605, doi:10.5194/bg-12-2597-2015, 2015.

Karstensen, J., Schütte, F., Pietri, A., Krahmann, G., Fiedler, B., Grundle, D., Hauss, H., Körtzinger, A., Löscher, C. R., Testor, P., Vieira, N., and Visbeck, M.: Upwelling and isolation in oxygendepleted anticyclonic modewater eddies and implications for nitrate cycling, Biogeosciences Discuss., doi:10.5194/bg-2016-34, in review, 2016.

Karstensen, J., Stramma, L., and Visbeck, M.: Oxygen minimum zones in the eastern tropical Atlantic and Pacific oceans, Prog. Oceanogr., 77, 331-350, 2008.

Kostianoy, A. G. and Belkin, I. M.: A Survey of Observations on Emtrathermocline Eddies in the World Ocean, in: Elsevier Oceanography Series, edited by: Nihoul, J. C. J. and Jamart, B. M., Elsevier, 1989.

Lachkar, Z. and Gruber, N.: A comparative study of biological production in eastern boundary upwelling systems using an artificial neural network, Biogeosciences, 9, 293-308, doi:10.5194/bg-9293-2012, 2012 
Lévy, M., Iovino, D., Resplandy, L., Klein, P., Madec, G., Tréguier, A. M., Masson, S., and Takahashi, K.: Large-scale impacts of submesoscale dynamics on phytoplankton: Local and remote effects, Ocean Model., 43-44, 77-93, 2012.

Levy, M., Klein, P., and Treguier, A. M.: Impact of sub-mesoscale physics on production and subduction of phytoplankton in an oligotrophic regime, J. Mar. Res., 59, 535-565, 2001.

Löscher, C. R., Fischer, M. A., Neulinger, S. C., Fiedler, B., Philippi, M., Schütte, F., Singh, A., Hauss, H., Karstensen, J., Körtzinger, A., Künzel, S., and Schmitz, R. A.: Hidden biosphere in an oxygen-deficient Atlantic open-ocean eddy: future implications of ocean deoxygenation on primary production in the eastern tropical North Atlantic, Biogeosciences, 12, 7467-7482, doi:10.5194/bg-12-7467-2015, 2015.

Lukas, R. and Santiago-Mandujano, F.: Extreme water mass anomaly observed in the Hawaii ocean time-series, Geophys. Res. Lett., 28, 2931-2934, 2001.

Luyten, J. R., Pedlosky, J., and Stommel, H.: The ventilated thermocline, J. Phys. Oceanogr., 13, 292-309, 1983.

Marchesiello, P., McWilliams, J. C., and Shchepetkin, A.: Equilibrium structure and dynamics of the California Current System, J. Phys. Oceanogr., 33, 753-783, 2003.

Martin, A. P. and Richards, K. J.: Mechanisms for vertical nutrient transport within a North Atlantic mesoscale eddy, Deep-Sea Res. Pt. II, 48, 757-773, 2001.

McGillicuddy, D. J., Anderson, L. A., Bates, N. R., Bibby, T., Buesseler, K. O., Carlson, C. A., Davis, C. S., Ewart, C., Falkowski, P. G., Goldthwait, S. A., Hansell, D. A., Jenkins, W. J., Johnson, R., Kosnyrev, V. K., Ledwell, J. R., Li, Q. P., Siegel, D. A., and Steinberg, D. K.: Eddy/wind interactions stimulate extraordinary mid-ocean plankton blooms, Science, 316, 1021-1026, 2007.

McGillicuddy, D. J., Robinson, A. R., Siegel, D. A., Jannasch, H. W., Johnson, R., Dickeys, T., McNeil, J., Michaels, A. F., and Knap, A. H.: Influence of mesoscale eddies on new production in the Sargasso Sea, Nature, 394, 263-266, 1998.

McWilliams, J. C.: Submesoscale, Coherent Vortices in the Ocean, Rev. Geophys., 23, 165-182, 1985.

Menkes, C. E., Kennan, S. C., Flament, P., Dandonneau, Y., Masson, S., Biessy, B., Marchal, E., Eldin, G., Grelet, J., and Montel, Y.: A whirling ecosystem in the equatorial Atlantic, Geophys. Res. Lett., 29, 48-41-48-44, 2002.

Messié, M., Ledesma, J., Kolber, D. D., Michisaki, R. P., Foley, D. G., and Chavez, F. P.: Potential new production estimates in four eastern boundary upwelling ecosystems, Prog. Oceanogr., 83, 151-158, 2009.

Mittelstaedt, E.: The ocean boundary along the Northwest African Coast - circulation and oceanographic properties at the seasurface, Prog. Oceanogr., 26, 307-355, 1991.

Molemaker, M. J., McWilliams, J. C., and Dewar, W. K.: Submesoscale Instability and Generation of Mesoscale Anticyclones near a Separation of the California Undercurrent, J. Phys. Oceanogr., 45, 613-629, 2015.

NASA: National Aeronautics and Space Administration, Modis Aqua Level 3 Chlorophyll, available at: http://oceancolor.gsfc. nasa.gov, last access: 5 January 2016.

Nagai, T., Gruber, N., Frenzel, H., Lachkar, Z., McWilliams, J. C., and Plattner, G. K.: Dominant role of eddies and filaments in the offshore transport of carbon and nutrients in the California Current System, J. Geophys. Res.-Oceans, 120, 5318-5341, 2015.
Nencioli, F., Dong, C., Dickey, T., Washburn, L., and McWilliams, J. C.: A Vector Geometry-Based Eddy Detection Algorithm and Its Application to a High-Resolution Numerical Model Product and High-Frequency Radar Surface Velocities in the Southern California Bight, J. Atmos. Ocean. Technol., 27, 564-579, 2010.

Nof, D., Pichevin, T., and Sprintall, J.: "Teddies" and the origin of the Leeuwin Current, J. Phys. Oceanogr., 32, 2571-2588, 2002.

Oliver, K. I. C., Eldevik, T., Stevens, D. P., and Watson, A. J.: A Greenland Sea Perspective on the Dynamics of Postconvective Eddies, J. Phys. Oceanogr., 38, 2755-2771, 2008.

Omand, M. M., D’ Asaro, E. A., Lee, C. M., Perry, M. J., Briggs, N., Cetinic, I., and Mahadevan, A.: Eddy-driven subduction exports particulate organic carbon from the spring bloom, Science, 348, 222-225, 2015.

Pastor, M. V., Pelegrí, J. L., Hernández-Guerra, A., Font, J., Salat, J., and Emelianov, M.: Water and nutrient fluxes off Northwest Africa, Cont. Shelf Res., 28, 915-936, 2008.

Pauly, D. and Christensen, V.: Primary production required to sustain global fisheries, Nature, 374, 255-257, 1995.

REMSS: Remote Sensing Systems, Microwave-Infrared optimal interpolated Sea Surface Temperature, available at: http://www. remss.com/measurements/sea-surface-temperature/, last access: 5 January 2016.

Richardson, P. L., Price, J. F., Walsh, D., Armi, L., and Schröder, M.: Tracking Three Meddies with SOFAR Floats, J. Phys. Oceanogr., 19, 371-383, 1989.

Riser, S. C., Owens, W. B., Rossby, H. T., and Ebbesmeyer, C. C.: The Structure, Dynamics, and Origin of a Small-Scale Lens of Water in the Western North-Atlantic Thermocline, J. Phys. Oceanogr., 16, 572-590, 1986.

Schmidtko, S., Johnson, G. C., and Lyman, J. M.: MIMOC: A global monthly isopycnal upper-ocean climatology with mixed layers, J. Geophys. Res.-Oceans, 118, 1658-1672, 2013.

Schütte, F., Brandt, P., and Karstensen, J.: Occurrence and characteristics of mesoscale eddies in the tropical northeastern Atlantic Ocean, Ocean Sci., 12, 663-685, doi:10.5194/os-12-663-2016, 2016a.

Schütte, F., Karstensen, J., Krahmann, G., Hauss, H., Fiedler, B., Brandt, P., and Visbeck, M., Characterization of dead-zone eddies in the tropical Northeast Atlantic, doi:10.1594/PANGAEA.860778, 2016b.

Shapiro, G. I. and Meschanov, S. L.: Distribution and Spreading of Red-Sea Water and Salt Lens Formation in the Northwest IndianOcean, Deep-Sea Res., 38, 21-34, 1991.

Stramma, L., Bange, H. W., Czeschel, R., Lorenzo, A., and Frank, M.: On the role of mesoscale eddies for the biological productivity and biogeochemistry in the eastern tropical Pacific Ocean off Peru, Biogeosciences, 10, 7293-7306, doi:10.5194/bg-10-72932013, 2013.

Stramma, L., Johnson, G. C., Sprintall, J., and Mohrholz, V.: Expanding oxygen-minimum zones in the tropical oceans, Science, 320, 655-658, 2008.

Stramma, L., Visbeck, M., Brandt, P., Tanhua, T., and Wallace, D.: Decreasing oxygen in the oxygen minimum zone of the eastern tropical North Atlantic, Geochim. Cosmochim. Ac., 73, A1281A1281, 2009.

Taupier-Letage, I., Puillat, I., Millot, C., and Raimbault, P.: Biological response to mesoscale eddies in the Algerian Basin, J. Geophys. Res.-Oceans, 108, 2003. 
Thomas, L. N.: Formation of intrathermocline eddies at ocean fronts by wind-driven destruction of potential vorticity, Dynam. Atmos. Oceans, 45, 252-273, 2008.

Thomsen, S., Kanzow, T., Krahmann, G., Greatbatch, R. J., Dengler, M., and Lavik, G.: The formation of a subsurface anticyclonic eddy in the Peru-Chile Undercurrent and its impact on the nearcoastal salinity, oxygen and nutrient distributions, J. Geophys. Res.-Oceans, 121, 476-501, doi:10.1002/2015JC010878, 2015.

Van Aken, H., Van Heijst, G., and Maas, L.: Observations of fronts in the North Sea, J. Mar. Res., 45, 579-600, 1987.

von Schuckmann, K., Brandt, P., and Eden, C.: Generation of tropical instability waves in the Atlantic Ocean, J. Geophy.s Res.Oceans, 113, C08034, doi:10.1029/2007JC004712, 2008.
Wyrtki, K.: The oxygen minima in relation to ocean circulation, Deep-Sea Res., 9, 11-23, 1962.

Zenk, W., Klein, B., and Schroder, M.: Cape Verde Frontal Zone, Deep-Sea Res. Pt. I, 38, S505-S530, 1991.

Zhang, Z., Zhang, Y., Wang, W., and Huang, R. X.: Universal structure of mesoscale eddies in the ocean, Geophys. Res. Lett., 40, 3677-3681, 2013.

Zhurbas, V., Stipa, T., Malkki, P., Paka, V., Golenko, N., Hense, I., and Sklyarov, V.: Generation of subsurface cyclonic eddies in the southeast Baltic Sea: Observations and numerical experiments, J. Geophys. Res.-Oceans, 109, C05033, doi:10.1029/2003JC002074, 2004. 